\title{
Fatigue of Drillstring: State of the Art
}

\author{
O. Vaisberg ${ }^{1}, 0$. Vincké ${ }^{1}$, G. Perrin ${ }^{1}$, J.P. Sarda ${ }^{1}$ and J.B. Faÿ ${ }^{1}$ \\ 1 Institut français du pétrole, division M écanique appliquée, 1 et 4, avenue de Bois-Préau, 92852 Rueil-M almaison Cedex - France \\ e-mail: olivier.vaisberg@ifp.fr - olivier.vincke@ifp.fr - gilles.perrin@ifp.fr - j-paul.sarda@ifp.fr - j-baptiste.fay@ifp.fr
}

Résumé - Fatigue des tiges de forage : état de l'art — La rupture des tiges de forage est un problème coûteux dans l'industrie de ce secteur. Bien que de nombreux spécialistes se soient penchés sur ce point, la fréquence des ruptures demeure toujours importante. Les ruptures par torsion ou par tension restent toutefois limitées, car les causes en sont connues et peuvent être aisément corrigées, en revanche, les ruptures par fatigue sont plus difficilement appréhendées.

Le présent article se propose d'établir un état de l'art sur la fatigue des tiges de forage. La prédiction et les calculs d'un dommage de fatigue sont ici abordés selon la méthode simpliste du cumul de dommage (somme de Miner) mais aussi de façon plus complexe, par l'utilisation des éléments de la mécanique de la rupture. Les méthodes d'inspection et leurs limitations sont discutées, des recommandations sont également émises. Par ailleurs, des tests de fatigue sont mis en œuvre face au risque humain ou environnemental. Cette étude précise les conditions de chargement, la fréquence des essais, le nombre et la taille des éprouvettes. Nous rappelons les effets d'un environnement corrosif ainsi que leur prévention, bien que ce sujet ne soit pas l'objet principal de cet article. Le dernier chapitre résume les différentes façons d'améliorer les tiges de forage. À ce titre, il aborde la géométrie, le design des connexions, les propriétés de l'acier telles que la résilience, le rechargement dur des tool-joints et l'inspection des garnitures de forage.

Mots-clés : tige de forage, garniture de forage, fatigue, rupture, calcul de dommage, inspection, tests de fatigue, effets de l'environnement, corrosion, amélioration, connexions vissées, tool-joints.

\begin{abstract}
Fatigue of Drillstring: State of the Art - Failure due to fatigue is a very costly problem in oil and gas industry. Many investigators have previously addressed this problem, but its frequency of occurrence is still excessive. Torque and tension can be correctly predicted but computations of fatigue duration are still approximate.

Regarding the fatigue failure of drillstring, this paper summarizes the state of the art. Prediction and calculation of fatigue duration are stated, including both history of the simplified approach based on Miner's rule and a few elements of the fracture mechanics theory. Existing inspection methods, their limitations and further recommendations are provided. Moreover, the fatigue tests are performed when human life and environment may be at risk. The loading conditions, the test frequency, the number and the size of test specimens are given. Environmental effects such as corrosion are recalled. Prevention and inhibitors are mentioned. Last chapter focuses on enhancement of drillstring. Drillpipes geometry improvement, connections re-design, steel properties such as toughness, tool-joints hardfacing and inspection of drillpipes are discussed.
\end{abstract}

Keywords: drillstring, drillstem, drillpipe, fatigue, failure, damage calculation, inspection, fatigue tests, environmental effects, corrosion, improvement, threaded connections, tool-joints. 


\section{IN TRO DUCTIO N}

Failure due to fatigue is a very costly problem in oil and gas industry. Although many investigators have previously addressed this problem, its frequency of occurrence is still excessive.

Drillstring failure occurs on 14-percent of all rigs and the resulting downtime costs roughly $\$ 106000$ per event $[1,2]$. A survey of all drilling problems reported worldwide over a 15-month period shows that 36-percent were due to stuck pipe. Stuck pipe cost estimates for the worldwide drilling industry range as high as $\$ 250$ million for this period [3].

Hill has analyzed 76 drillstring failures from 1987 to 1990 on three continents [4]. These incidents are costly because of the loss of rig time, tubular goods and even the well in some time. In 1992, one in seven wells are concerned. Failure causes can be estimated as follows.

- Fatigue is the main cause in 65-percent of the failures and has a significant impact in 12-percent.

- Combined excessive tension and torque give failures in 13-percent of the cases.

- Low toughness of material is mentioned for only 8-percent of the failures.

The same conclusion is issued in [5] where 73-percent of inspected drillpipes were defective because of fatigue cracks.

Torque and tension are correctly estimated but fatigue is still an approximate skill.

Mechanical stresses in drillstem, environmental and unusual conditions, such as corrosive mud, horizontal well, etc., should be predicted as accurately as possible in order to define the best drillstring assembly and then reduce fatigue failure. Planning an inspection program, before and while drilling is an important step. Monitoring results while drilling and tripping should be compared with theoretical models.

The first two points are developed in Section 1 and 2. Fatigue tests, presented in Section 3, are necessary to have a better understanding of both steel and equipment behavior.
Environmental conditions are listed in Section 4 but this is not the main subject of this paper. Section 5 focuses on improvement on drillstring, on manufacturing methodology and on material properties. Anyway, state of the art, limitations and improvement will be underlined.

\section{FATIGUE CALCULATIONS}

\subsection{General}

Fatigue damage is due to the reversed variations of the stresses, such as those induced when the drillpipe rotates in a curved section of a wellbore. Rotating a buckled pipe may also lead to rapid fatigue failure (Fig. 1). Fatigue troubles can be estimated from the number of cycles associated with the amplitude of the stress cycles.

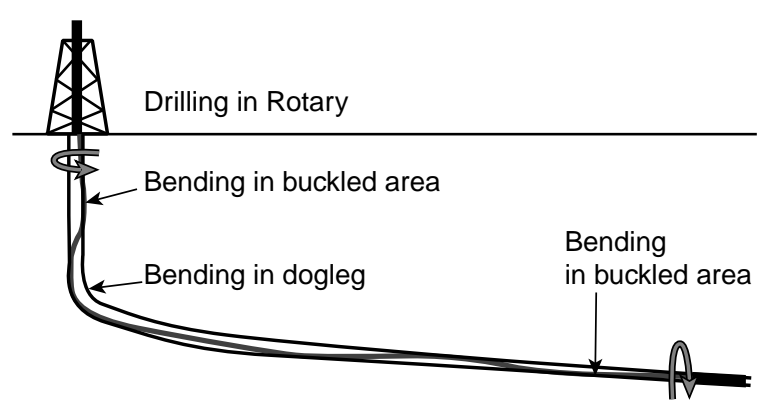

Figure 1

Fatigue may occurs when drillstring is crooked and rotated.

The material is indeed characterized by $S-N$ curve also called Wöhler curve where stress amplitude $(S)$ is given versus the maximum allowable number of cycles $\left(\log N_{f}\right)$, (Fig. 2). Failure is likely to occur when the working number of cycles is equal to the allowable number of cycles $N_{f}$. Other representations are the Haigh diagram (Fig. 3) [6] or the

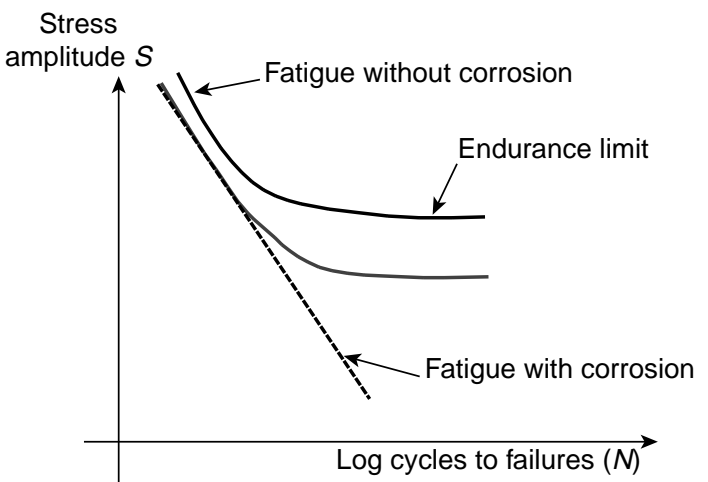

Figure 2

$S-N$ Curve

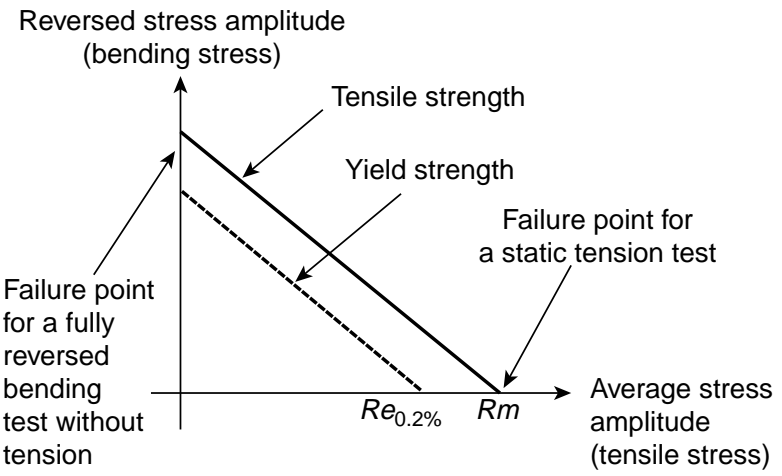

Figure 3

Haigh diagram [6]. 
Goodman diagram [7]. Cyclic stress amplitude is given versus average stress.

Loads applied on the drillpipe should be known in order to determine both permanent and cycling stresses. A calculation methodology is presented in the next section. Using the previous parameters, life duration can be estimated as detailed in Section 1.3. Nevertheless, vibration effects will be neglected as a first approach and we assume that they should be avoided as much as possible. Anyway, the Institut français du pétrole $(I F P)$ is presently studying the effects of dynamic vibration behavior of a complete drillstring using a finite element software where large displacement and friction effects are taken into account. For further details, refer to Section 6.

However, this simplified approach is empirical and lacks the physical basis necessary to consider the fatigue as a progressive and history dependent phenomenon. While working, microscopic cracks come out in the structure. Those cracks tend to gradually increase until their length is large enough to create the drillpipes failure: washout or twist-off may occur. Each step, initiation, propagation and failure can be modeled as shown in Section 1.4.

In the present section, corrosion will be ignored as it is described in Section 4.

\subsection{Drillpipe Stresses}

Most of the papers are based on Lubinski works [7, 8]. Regarding modified Goodman diagram, the reversed bending stress is the cycle stress amplitude, which is given versus the tensile or average stress.

In a modified Goodman diagram used at the endurance level, Lubinski [7] assumed a reduction of the endurance limit at low mean stress to allow for slip mark and wears on the pipe body. In addition, he assumed a cutoff on the mean stress level in noncorrosive mud at $67 \mathrm{ksi}$ (462 MPa) (Fig. 4).

Therefore, maximum reversed bending stress can be calculated in a maximum dogleg severity (DLS). Moreover, the greater the average tensile stress, the smaller is the maximum bending stress that the drillpipe may withstand.

Using modified Goodman diagram and tensile stress, maximum allowable reversed bending stress can be figured out. A maximum permissible dogleg severity can be found when resolving the differential equation of the elastic arc-ofcircle line for a given dogleg. This maximum allowable DLS is dependent on axial tensile load, weight on bit, weight on hook, bending moment and length between tool-joints and reaction force on wall at contact point. To simulate the relatively large bending stiffness of the tool-joint, the ends of the drillpipes were fully restrained. Main results for drillpipes under tension are as follows:

$$
c_{0}=c\left(\frac{K L}{\tanh K L}\right)
$$

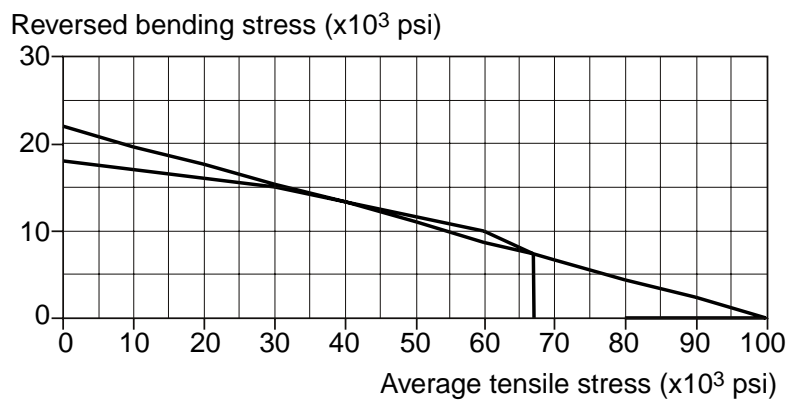

Figure 4

Modified Goodman diagram for Grade E drillpipe (as per Lubinski [7]).

where $c_{0}$ is the curvature of the drillpipe body near to the tool-joint, $c$, the permissible curvature of the dogleg (DLS) and $L$, half the length of the drillpipe. Note that gravity forces are neglected hereabove. $K$ is given by:

$$
K=\left(\frac{T}{E I}\right)^{\frac{1}{2}}
$$

where $T$ is the axial tension force, $E$, the modulus of elasticity of pipe material and $I$, the moment of inertia of the cross section of the drillpipe body.

The bending stress is finally given by:

$$
\sigma_{b}=\left(\frac{c_{0} E \cdot d}{2}\right)
$$

where $d$ is the diameter of the drillpipe body. Complete relationships for any other drillpipes configurations in dogleg are available in [7].

Lubinski has defined curves where the permissible dogleg severity, below which no fatigue damage of drillpipes may occur, can be estimated from the tensile load and the drillpipes characteristics. These curves used to prevent static failure are the bases of the "API-RP-7G" [9] (API is the American Petroleum Institute).

$\mathrm{Wu}$ [10] presents a model and a summary of Lubinski works. For the jointed drillpipes located in a dogleg, the axial tensile load tends to straighten the middle portion of the pipe. Therefore, maximum bending stress is located next to the tool-joint (Fig. 5). Regarding these maximum-bending stresses, assumption is performed that the drillpipe body does not contact the wellbore wall. If axial tensile loads are small, the drillpipe weight becomes dominant: the maximum bending stress may be located in the middle of the drillpipe. The axial compressive load tends to deflect further the middle portion of the pipe, where the maximum bending stress may occur (Fig. 6). Moreover, the maximum bending stresses calculated as before are on the conservative side because the drillpipe bending deflection is confined within 


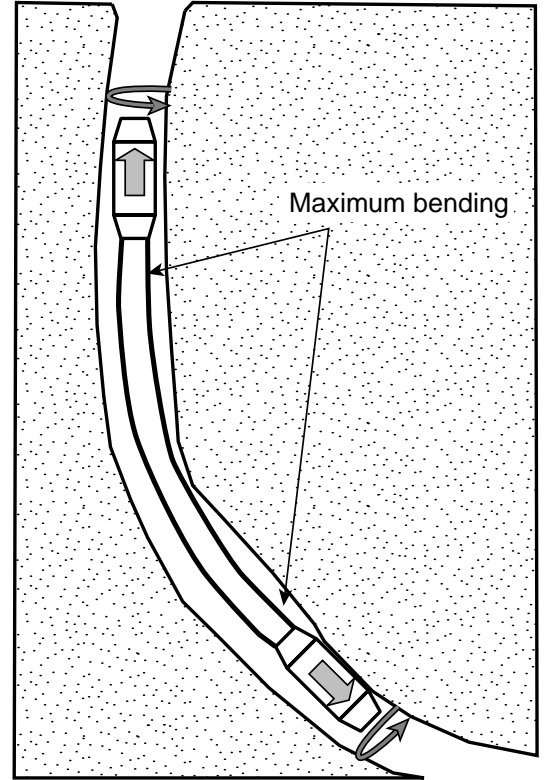

Figure 5

Maximum bending in tension drillpipe.

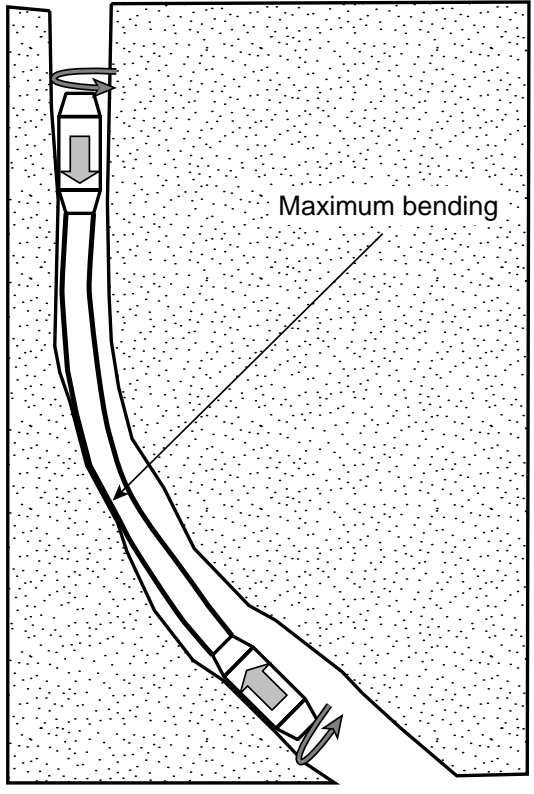

Figure 6

Maximum bending in compression drillpipe. the wellbore. No further calculations are carried out in order to take into account several contact points in the pipe body.

Based on field failure data analysis, full scale fatigue testing and finite element analyses, Sheppard [11] confirms that maximum bending stresses are in the vicinity of tooljoints.

Some authors suggest improvement on the Lubinski's model. Wu [12] or Paslay [13] add an "arc" boundary condition, as the contact is not a perfect point. Howard [14] overlays the well geometry by a sinusoidal profile in order to better model the bottom hole assembly (BHA) crooked trajectory.

This approach is empirical as calculation is performed in the local dogleg area where the contact points are supposed to be known. Assuming a corrosive or a notching environment, the $S-N$ curve used by Lubinski was modified by reducing or canceling endurance limits. Because S-N curve is the basic building block for this model, these effects may ruin this theory. Moreover, they did not account the threaded tool-joints as being a critical section; the whole analysis was concerned with drillpipes. Anyway it does not address the specification of cost-efficient nondestructive inspection intervals to avoid fatigue [2].

Regarding extended reach drilling, Smith [15] and Hill [16] have studied the reversed bending stress when the pipe is buckled. The tension state, the stability forces and the mechanical characteristics of the hole affect buckling.

The methodology to check buckling is the following:

- Check whether the drillpipe is buckled? Drillpipe areas which are likely to buckle are above the bottom hole assembly and above any severe dogleg. The drillpipe remains stable as long as the magnitude of mechanical compression does not exceed the critical buckling load (FC).

- If pipe is buckled, can we lower the weight on bit in order to reduce the compression forces?

- If weight on bit cannot be decreased, buckling tolerant components such as heavy weight drillpipes should be introduced in the buckled areas.

This paragraph will focus on the critical buckling load calculation. Assuming that stability and pressure forces are ignored, i.e side loads applied on drillpipe body, DawsonPasley relationship [17] is used provided that the drillpipes are rotated in a straight-wellbore. The critical buckling load in a straight wellbore could be predicted by the relationship (4):

$$
F_{C}=2 \sqrt{\frac{E I w K_{B} \sin \theta}{r}}
$$

where $E$ is the young modulus, $I$, the moment of inertia, $w$, the weight percent length in air of a drillstring component, $K_{B}$, the mud buoyancy factor, $\theta$, the hole inclination departure from verticality, $r$, the radial clearance between pipe and hole. Formula (4) is thought to be conservative [16] when the hole is not enlarged, as it does not consider the benefit gained from the presence of tool-joints on the drillpipe.

In curved wellbores such as building or dropping wellbores, He and Kylingstad Equation [18] is used. The equation for dimensionless buckling load is the following:

$$
\bar{F}_{C}^{4}-\left[\left(\bar{\phi}^{\prime}\right)^{2}+\left(\bar{\theta}^{\prime}\right)^{2}\right] \bar{F}_{C}^{2}-2 \bar{\theta}^{\prime}\left(\bar{F}_{C}\right)-1=0
$$


where $\bar{F}_{c}$ is the dimensionless critical buckling load, $\bar{\phi}$ and and $\bar{\theta}$ are respectively the dimensionless walk rate and build rate. They are defined as follows.

$$
\begin{aligned}
& \bar{\phi}^{\prime}=\phi^{\prime} \sqrt{\frac{\beta E I \sin \theta}{r W b}} \\
& \bar{\theta}^{\prime}=\theta^{\prime} \sqrt{\frac{\beta E I}{r W b \sin \theta}}
\end{aligned}
$$

where $\beta$ is a constant ( 4 for sinusoidal buckling when rotating, 8 for helical buckling when sliding), $\phi$ ' is the walk rate (deg/inches), $\theta^{\prime}$ is the build rate (deg/inches) and $\theta$ is the wellbore inclination (radians). Other values have the same meaning as those described in Equation (4). Critical buckling for curved wellbore is therefore determined by finding $\bar{F}_{c}$ the largest positive real root of Equation (5), solving for the Dawson-Paslay buckling load $F_{C}(E q$. (4)) and multiplying the two.

With a hole angle greater than $68^{\circ}$, friction coefficient is close to 0.4 [15]. Extra compressive axial forces must be applied to the pipe to push and advance the string and to put enough weight on the bit.

When designing drillstring and bottom hole assembly, the following recommendations for reducing buckling and vibrations should be respected.

The neutral point should be located in the larger diameter bottom drill collars. Larger size of heavy weight drillpipe (HWDP) should be introduced to reduce the section modulus ratios close to 3:1 between the drill collars and the HWDP. For further details, see Section 5.4. Stiffness or inertia moment is increased by around 15-percent with spiraled HWDP compared to the standard construction featuring only one central upset. Straight hole conditions should be maintained by running a packed hole assembly or a pendulum, depending on drilling conditions (Fig. 7). Large diameter drill collars, close to hole size, near the bit, would supply weight for the bit and reduce bending in the connections. Proper stabilization should be calculated to prevent bending and whipping action. See Figures 7 to 9 for further information. Rotary speed should be reduced as much as possible, e.g. 80-90 rpm (rotations per minute), to reduce whipping action. Stabilizers should be carefully selected as well as diameter, blade profile, coverage and hardfacing in order to maintain a constant hole diameter.

Anyway, buckling behavior and stabilization should always be calculated: rotating a buckled drillstring should be avoided as the reversed bending stress will lead to rapid fatigue failure.

\subsection{Life Duration}

Lubinski and Hansford outstanding works [7, 8] are quite useful to give figures for the design step, i.e. to predict the best permissible dogleg. However cumulative damage and failure prediction could be found out as they are based on stresses histogram versus cycles number for each drillpipe. Figure 10 gives one of the common methodologies to estimate cumulative damage [1]. Palmgren-Miner's rule is used, where the total damage is the addition of each damage occurred at each cycle, regardless of pipe's previous load history. However, it is known that the sequence of cyclic loading could have an effect on the damage accumulation, e.g., if the loading sequence is from low-to-high loads, then cumulative damage could be more than 1; conversely, for high-to-low loads, cumulative damage could be less than 1 .

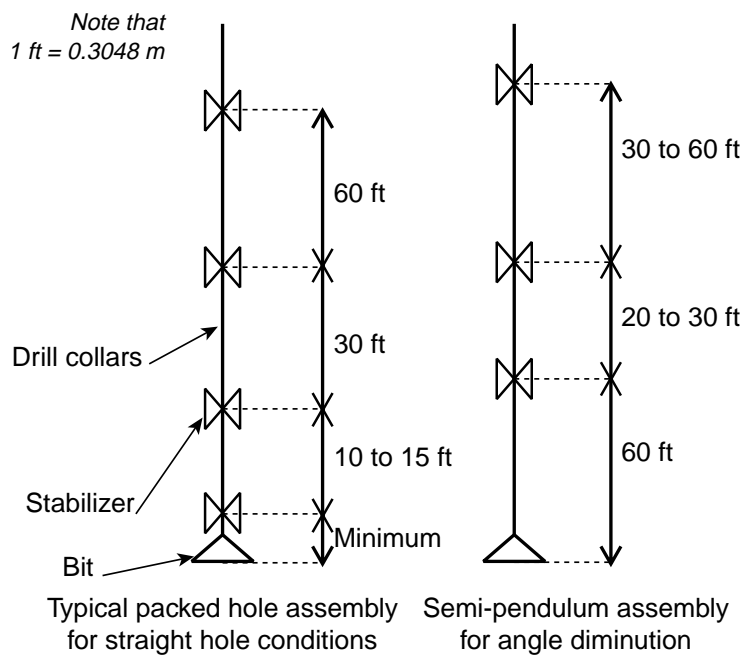

Figure 7

Typical assemblies with several stabilizers in vertical hole.
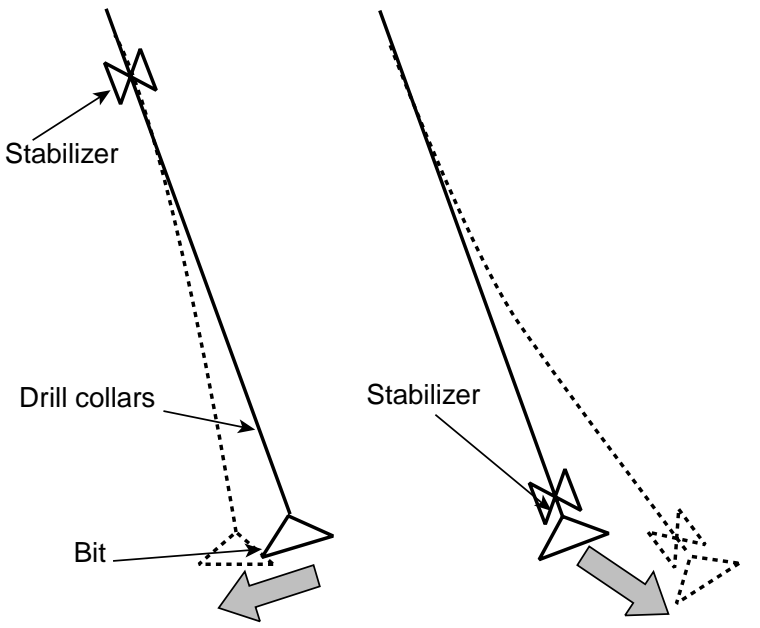

Assembly for angle reduction

Assembly for angle increase

Typical assemblies with one stabilizer in nonvertical hole. 


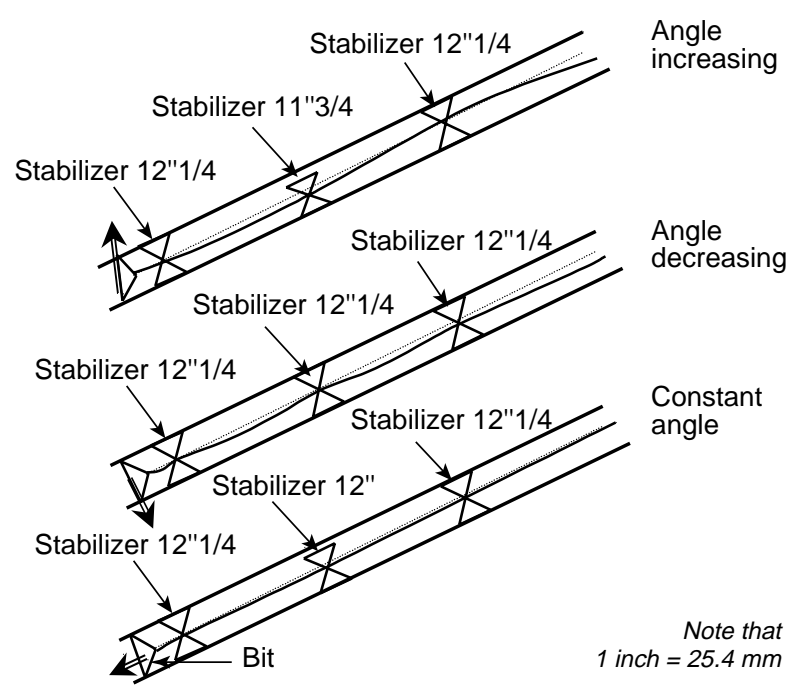

Figure 9

Typical assemblies with several stabilizers in nonvertical hole.

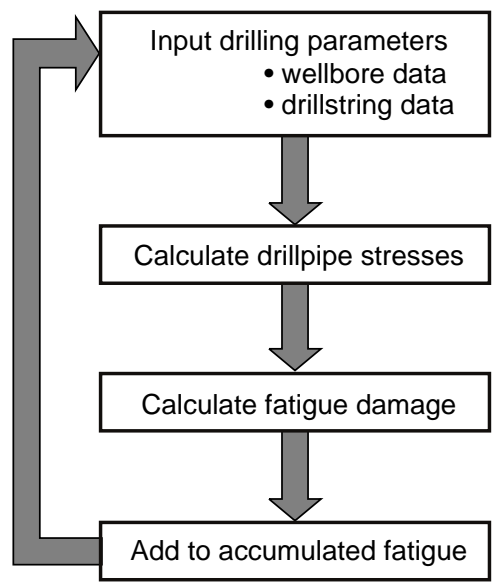

Figure 10

Cumulative damage methodology based on Miner's rule.

Baryshnikov [19] reports that fatigue life increases by 1.5-2.0 times for full-scale tests carried out under dynamic loads lower than the fatigue limit.

The alternating bending stress should be increased by stress concentration factor (SCF) provided that it is not already accounted for in $S$ - $N$ curves. The stress concentration factor is the ratio of maximum stress calculated (e.g. finite element analysis) in the high loaded area to nominal pipebody stress. For examples, Rahman [20] recommends SCFs figures of 1.07, 1.15 and 1.6 respectively for die-marks depth of $0.0004 "(0.0102 \mathrm{~mm}), 0.0012 "(0.0305 \mathrm{~mm})$ and 0.01 " $(0.254 \mathrm{~mm})$. Therefore, dies of gripping system which mark the pipe surface during making and breaking operation should be minimized as they cause stress concentrations. These SCFs can be computed by finite element analyses.
Grondin [21] indicates that maximum stress concentration factors for standard internal-/external-/upset geometry are 1.19 for axial tension and 1.13 for pure bending.

Tafreshi and Dover [22] have carried out finite element analyses on several standard tool-joints. SCF figures are given for standard and modified NC46 connections. Maximum SCF may vary within a range of 3.29 to 8.56 , depending on the pin or box thread profile.

Anyway, all flaws should be reflected by appropriate stress concentration factors.

After evaluation of a stress concentration factor, a safety factor should be applied to account for static, dynamic, vibration loads, corrosion, make-up torque, etc. Baryshnikov [19] recommends a safety factor between 1.5 to 2.0 depending on the drilling technology and well conditions. Empirical functions exist such as the following equation, given in [19]:

$$
K_{s}=\frac{M_{f l}}{M_{a}}\left(1-\frac{Q_{t}}{Q_{t y}}\right)
$$

where $K_{s}$ is the safety factor, $M_{f l}$, the fatigue limit as a bending moment, $M_{a}$, the largest long-duration cyclic bending load, $Q_{t}$, the axial tensile load, and $Q_{t y}$, the maximum axial tensile load for downhole tool yield.

While drilling, one of the equations that gives the number of cycles that pipe has experienced in a dogleg is also given by Zeren [23]:

$$
n=60 \cdot r p m \cdot \frac{L}{D R}
$$

where $n$ is the number of cycles, rpm, the rotary speed, $L$, the dogleg interval ( $\mathrm{ft}$ ) and $D R$, the drilling rate $(\mathrm{ft} / \mathrm{h})$. Note that one foot equals $0.3048 \mathrm{~m}$.

The fatigue damage after passing a dogleg at known tension and curvature is:

$$
\frac{n}{N}
$$

where $n$ is the number of cycles, $N$, the total useful life (in cycles). $N$ is given by $S-N$ curve at the stress level corresponding to borehole curvature and pipe tension.

While drilling, more damage is done at higher rotary speed (rpm) and at lower drilling rate. The fatigue damage is inversely linearly proportional to the drilling rate and proportional to rpm.

During rotating off bottom, the fatigue damage is not negligible in the pipe passing through a given dogleg interval.

Existing fatigue damage for a given drillpipe will be added to damage cumulated when passing "new" dogleg intervals.

Grondin [21] has compared Lubinski's life duration results with a finite element analysis: Lubinski's approach is 
conservative due to the fact that he has ignored the secondorder nonlinear effects of contact. Thus, the bending stress is overestimated whereas the noncorrosive $S-N$ curves are nonconservative.

Ertas [24-25] alters the bending stress by a ratio in order to take into account mean stress due to nominal tension. The modification is based on Goodman line where the ratio $R$ depends on axial stress $\sigma_{m}$ and ultimate tensile strength of drillpipe material $S_{u}$ as follows:

$$
R=\frac{S_{U}}{S_{U}-\sigma_{m}}
$$

This approach uses finite element analyses in a local dogleg area.

$\mathrm{Wu}$ [10] changes the typical $S-N$ curves to take into account the effects of axial load. The Goodman line is used to consider this mean stress effect as axial tensile load reduces fatigue bending stress whereas axial compressive load increases fatigue bending stress (Fig. 11).

$S-N$ curves must also be modified to reflect corrosion effect. This is the Section 4 purpose.

\subsection{Fracture Mechanics}

Due to the increase of fracture mechanics studies, fatigue life duration of structure highly loaded in low cycles can be predicted quite accurately. High reversed bending loads and low cycles fatigue may modify the steel hardening essentially made for high tensile loads. Theory [6] developed hereunder is at ambient temperature i.e. without corrosion nor creeping effects. Plastic viscosity is negligible as well.

Life duration of a structure can be broken down in three main stages as recalled in Figures 12 and 13. Firstly, under cyclic stresses, accommodation is the prevalent mode. Initiation is the next step when microscopic cracks appear near surface discontinuity and grow across several grains controlled mainly by shear stresses. These phases correspond to roughly more than 80-percent of life duration and unfortunately they can hardly be reliably inspected. Keeping cyclic loads, one of the microscopic cracks will grow. It is perpendicular to and controlled by the maximum tensile stress. Propagation of this crack leads rapidly to failure by either brittle fracture or gross plastic deformation. High stress concentration areas such as threaded connections, upset area or slip die-marks tend to accelerate the crack propagation.

The total predicted fatigue life is the addition of the fatigue-crack-initiation duration $N_{I}$ plus the fatigue-crackpropagation duration $N_{P}$.

Fatigue life calculation using fracture mechanics can be summarized as follows:

1 estimation of stress history as a function of time $\sigma(t)$;

2 representation of the stress history by $n_{i}$ stress ranges $\Delta \sigma_{i}$ at $n_{i}$ cycles;

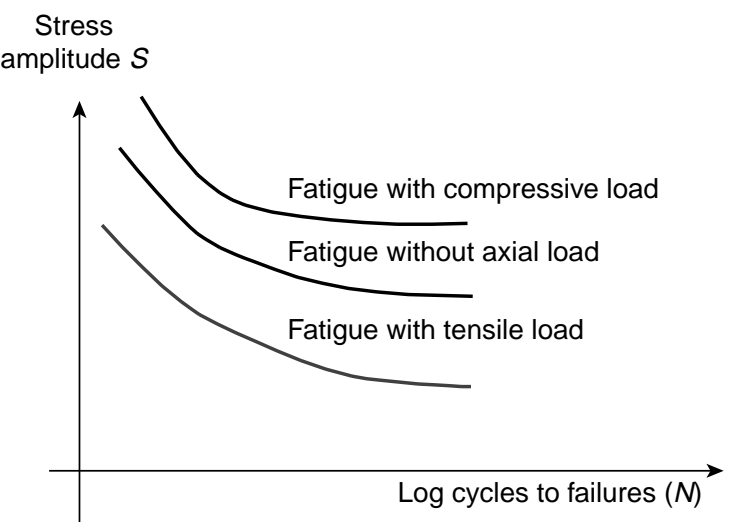

Figure 11

Axial load effects on $S-N$ curve.

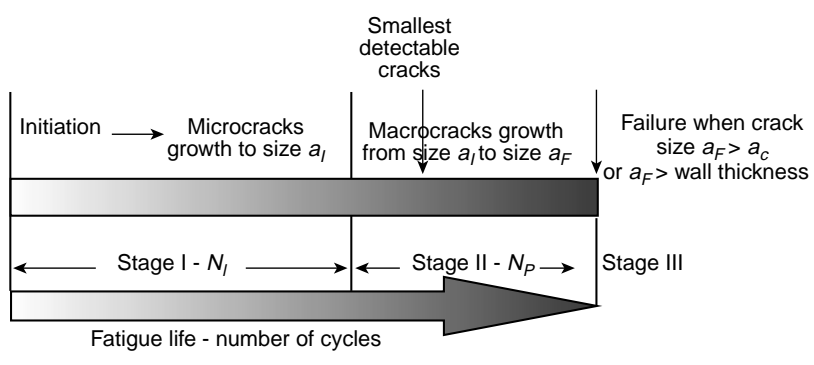

Figure 12

Fatigue life duration.

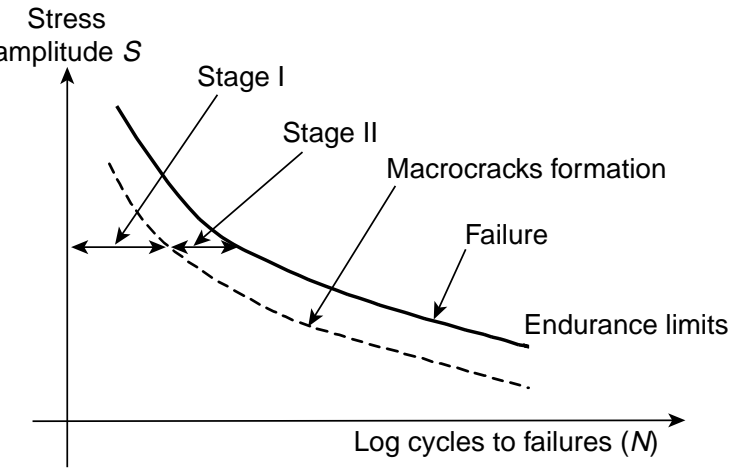

Figure 13

Fatigue life and $S$ - $N$ curve.

3 increasing the stresses by stress concentration factor and safety factor if necessary;

4 calculation of the fatigue-crack-initiation life $N_{I}$ and measurement of the initial crack depth $a_{i}$;

5 calculation of the fatigue-crack-propagation life $N_{p}$ where the crack increases from a size $a_{i}$ to a size $a_{F}$;

6 calculation of a critical crack size $a_{C}$;

7 failure will occur if $a_{F}>a_{C}$. 
Further details are given hereunder regarding point 3 . The stress-concentrated area ahead of a notch root, such as die-mark, thread root or groove, is the location where accumulation of dislocations yields to initiation of a microscopic crack at the surface.

The theoretical stress concentration factor should be used as proposed by Ikiwa and Ohira and reported by Placido [26], where the micro-discontinuities are considered as notches. The equation is the following:

$$
K_{t}=1+2 \sqrt{\frac{t}{r}}
$$

where $K_{t}$ is the approximated theoretical stress concentration factor, $t$ is the notch depth and $r$, the notch tip radius. Less conservatively, the notch factor $K_{f}$ proposed by Peterson is also given by Placido [26] as follows:

$$
K_{f}=1+\frac{K_{t}-1}{1+\frac{a}{r}}
$$

where $a$ is the length parameter estimated for steel by relationship (14).

$$
a=\left(\frac{300}{\sigma_{u}}\right)^{1.8} \cdot 10^{-3}
$$

where $a$ is in inches and $\sigma_{u}$ is the ultimate tensile strength in ksi. Note that one inch equals $25.4 \mathrm{~mm}$ and one ksi equals 6.89 MPa.

Point 4 is developed hereafter. The fatigue-crack-initiation life $N_{I}$ is calculated for a threaded connection by elastoplastic finite element analyses as a function of the stress parameter according to relationship (15):

$$
N_{I}=K[\Delta \sigma r(d 0)]^{-n}
$$

where $K$ and $n$ are constant depending on steel characteristics and determined by fatigue tests. Parameter $d_{0}$ is a distance measured from the notch root. These parameters are independent of the tool-joint geometry but they only depend on the steel properties. $\Delta \sigma_{r}$ is the reversed stress or the representation of the stress history range.

The crack initiation size $a_{i}$ is the initial fault size, which can be measured by microscope for example.

The mean stress has significant impact on the fatigue crack-initiation life [27], particularly when the cyclic stress is small. The fatigue initiation life is usually a function of the completely reversed stress or strain amplitude. The tensile mean stress increases the effective or equivalent completely reversed stress and then shortens fatigue life. Chen [27] uses a mean stress of 80-percent yield strength to simulate makeup torque stress in the pin, and 40 to 50-percent yield strength to simulate make-up torque stress in the box. He proposes an equation to predict the mean stress effects as a geometric mean of Morrow and Smith's equation as follows:

$$
\Delta \sigma_{r}=\left[\left(\frac{\sigma_{a}}{1-\frac{\bar{\sigma}}{M_{s}}}\right)\left(\left(\bar{\sigma}+\sigma_{a}\right) \cdot \sigma_{a}\right)^{\frac{1}{2}}\right]^{\frac{1}{2}}
$$

where the first factor is given by Morrow's Equation and the second one by Smith's Equation. $\Delta \sigma_{r}$ is again the equivalent completely reversed stress amplitude, $\sigma_{a}$, the applied stress amplitude, $\bar{\sigma}$, the applied mean stress and $M_{s}$, a fatigue strength coefficient.

The fatigue-crack-propagation life (point 5) is calculated from the predicted crack-initiation size $a_{i}$ to a critical crack size, $a_{C}$, or to penetration of wall thickness, whichever occurs first. This oligocyclic propagation is given by Paris's Equation [28, 29], which yields a crack distance of progression per cycle as follows:

$$
\frac{d a}{d N}=C \cdot \Delta K^{n}
$$

where $C$ and $n$ are coefficient depending on steel characteristics. Paris's law is the representation of the central part of the $d a / d N$ versus $\Delta K$ curve as represented in Figure 14. However, there are two asymptotes. The first one is defining final failure (18), the second one is a threshold $K_{t h}$ below which crack propagation is said to be null (19).

$$
\begin{aligned}
& K_{I} \rightarrow K_{I c} \Rightarrow \frac{d a}{d N} \rightarrow \infty \\
& K_{I} \rightarrow K_{t h} \Rightarrow \frac{d a}{d N} \rightarrow 0
\end{aligned}
$$

Lemaître and Chaboche propose a modified-Paris's law which includes the latest limits [30]. Mean stress is not correctly represented in Paris's law, but it can be easily corrected by a polynomial coefficient [30].

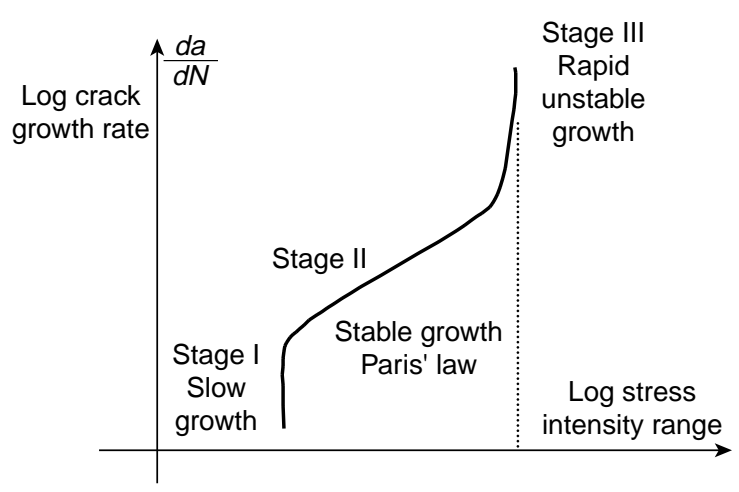

Figure 14

Paris's law. 
Final failure is characterized by criterion $K_{I}$ as per relationship (20), where for each failure area, a critical fault size noted a is measured. Calculus shows that:

$$
K_{I}=1.12 \sigma_{r} \sqrt{\pi \frac{a}{Q}}
$$

with $\sigma_{r}$, the reversed stress applied, and $Q$ is called flaw shape parameter. Ertas [28] proposes the following estimation of Q:

$$
\sqrt{Q}=\sqrt{\phi^{2}-0.212\left(\frac{\sigma_{r}}{\sigma_{y e}}\right)^{2}}
$$

$\sigma_{r}$ is still the reversed stress applied and $\sigma_{y e}$ is the drillpipe yield stress.

In (21), elliptical integral can be approximated by:

$$
\phi=\frac{3 \pi}{8}+\frac{\pi \cdot a^{2}}{8 c^{2}}
$$

assuming that the crack has a semi-elliptical shape of length $c$ and depth $2 a$ (Fig. 15).

Similarly, $K_{I c}$ is defined by (23), (point 6):

$$
K_{I c}=1.12 \sigma_{\max } \sqrt{\pi \frac{a_{c}}{Q}}
$$

As a conclusion, the method presented in this section is more accurate than the Miner's law but the condition $a_{F}>a_{C}$ is determinist. Moreover, close to the threshold, the Paris's law is not available for calculation due to the asymptote definition.

Another improvement is the probabilistic approach. The method is the same as the latest but stress history is a spectrum of stresses and spectral calculation uses Fourier transforms.

Ertas [25] concludes that fracture approach is less conservative than cumulative fatigue damage approach.
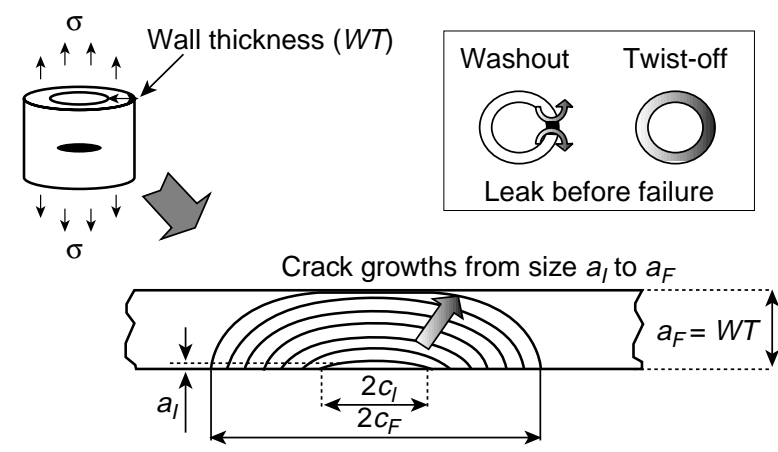

Figure 15

Semi-eliptical surface crack in drillpipe.
However, $S-N$ curve plus Miner's rule is still largely used because this method is quite easy to use. But $S$ - $N$ curves are the average of a band obtained from the scatter of a large number of plotted points, and they are representative of reduced scale specimens failure.

\section{METHODOLOGY AND IN SPECTION}

The purpose of this section is to describe existing inspection methods, their limitation and then to provide recommendations.

\subsection{General}

Hill has issued interesting studies [31] on inspection and qualification of drillpipes. Due to the additional economic risks of deep, hard or horizontal drilling, the inspection and acceptance of drillstring components should be based on their compliance with API and user standard.

Proper drillstring inspection should not be considered as reliable according to a "report" or a "certification" because API guidelines or quality control steps may not be followed by Inspection Companies. Moreover, API standards for used drillstem may not take into account deep or critical drilling.

\subsection{Inspection Procedure}

Inspection can be broken down in three steps [31]:

- determining the acceptance standards to be applied;

- deciding which inspection methods will be used by contractor and then conducted by inspection contractor;

- ensuring that the inspections are performed correctly in economically involving the operator.

Point 2 is unfortunately not addressed in "API-RP-7G" [9]. This quality process control should always be specified; Hill has defined complete recommendations in "Standard DS-1" [32], where a category from 1 through 5 is stated. For further details, see the Section "Inspection Tables" in [32]. Likewise, Shell Expro and Exxon [33] have issued a North Sea inspection specification document. Table 1 summarizes the inspection methods given in this specification (see also Figs 16 to 18).

Sweet [34] reports that point 3 can be monitored according to three levels depending on the probability of confidence in getting what the customer has asked: specifying, auditing or enforcing. Local company personnel or third party inspection services to supplement local inspection services should be required if necessary. Audits will also extend to machine and fabrication shops to ensure components are refurbished and manufactured in accordance with the required specifications.

The customer is responsible for listing the drillstem to be inspected, setting the inspection program and acceptance 
TABLE 1

Summary of inspection methods (as per Shell Expro and Exxon [33])

\begin{tabular}{|c|c|}
\hline Drillstring components & Inspections methods required \\
\hline $\begin{array}{l}\text { Drill collars and heavy-weight drillpipes } \\
\text { Connections, tong areas } \\
\text { Slip and elevator recesses } \\
\text { Center pads, harbanded areas }\end{array}$ & $\begin{array}{l}\text { Wet fluorescent magnetic particle } \\
\text { Visual } \\
\text { Dimensional }\end{array}$ \\
\hline $\begin{array}{l}\text { Drill collars and heavy-weight drillpipes } \\
\text { (Nonferromagnetic) } \\
\text { Connections, tong areas } \\
\text { Slip and elevator recesses } \\
\text { Center pads, harbanded areas }\end{array}$ & $\begin{array}{l}\text { Liquid penetrant } \\
\text { Visual } \\
\text { Dimensional }\end{array}$ \\
\hline $\begin{array}{l}\text { Other bottom hole assembly tools } \\
\text { Connections, tong areas, } \\
\text { Slip and elevator recesses, } \\
\text { Center pads, harbanded areas, } \\
\text { Other high stress areas }\end{array}$ & $\begin{array}{l}\text { Wet fluorescent magnetic particle } \\
\text { Visual } \\
\text { Dimensional }\end{array}$ \\
\hline $\begin{array}{l}\text { API Drillpipes } \\
\text { Connections, tool-joints } \\
\text { Slip and upset areas }\end{array}$ & $\begin{array}{l}\text { Wet fluorescent magnetic particle } \\
\text { Visual } \\
\text { Dimensional }\end{array}$ \\
\hline $\begin{array}{l}\text { API Drillpipes, } \\
\text { Pipe body, slip and upset areas }\end{array}$ & $\begin{array}{l}\text { Dimensional } \\
\text { Ultrasonic wall thickness } \\
\text { Visual } \\
\text { Electromagnetic drillpipe body } \\
\text { Ultrasonic drillpipe upset area } \\
\text { Prove-up }\end{array}$ \\
\hline
\end{tabular}

\begin{tabular}{|c|c|c|}
\hline Tool-joint (box) & Body & Tool-joint (pin) \\
\hline $\begin{array}{l}\text { - damages on external surface } \\
\text { - damages on threads } \\
\text { - box swell } \\
\text { - abrasion/erosion/hammering } \\
\text { - wear and mechanical damage } \\
\text { - } O D^{1} \text { reduction } \\
\text { - wall thickness reduction } \\
\text { - straigthness } \\
\text { - cracks in threads } \\
\text { - longitudinal cracks in box } \\
\text { external surface }\end{array}$ & $\begin{array}{l}\text { - wall thickness and } \\
\text { diameter }\left(O D / I D^{1}\right) \text { : minimal } \\
\text { section required } \\
\text { - shrinkage, necking, collapse, } \\
\text { hammering, stretching, } \\
\text { straigthness, wearing, crushing, } \\
\text { swell, etc } \\
\text { - longitudinal and transverse cracks } \\
\text { - corrosion pits (internal } \\
\text { and external) } \\
\text { - mechanical damage } \\
\text { - die-marks }\end{array}$ & $\begin{array}{l}\text { - damages on } \\
\text { external surface } \\
\text { - damages on threads } \\
\text { - threads stretching } \\
\text { - pin thread profile } \\
\text { and pin lead } \\
\text { - abrasion/erosion } \\
\text { /hammering } \\
\text { - wear and } \\
\text { mechanical damage } \\
\text { - OD1 reduction } \\
\text { - cracks in threads }\end{array}$ \\
\hline
\end{tabular}

Figure 16

Typical flaws in drillpipe. 
3- Inspection of swell (bell shape)

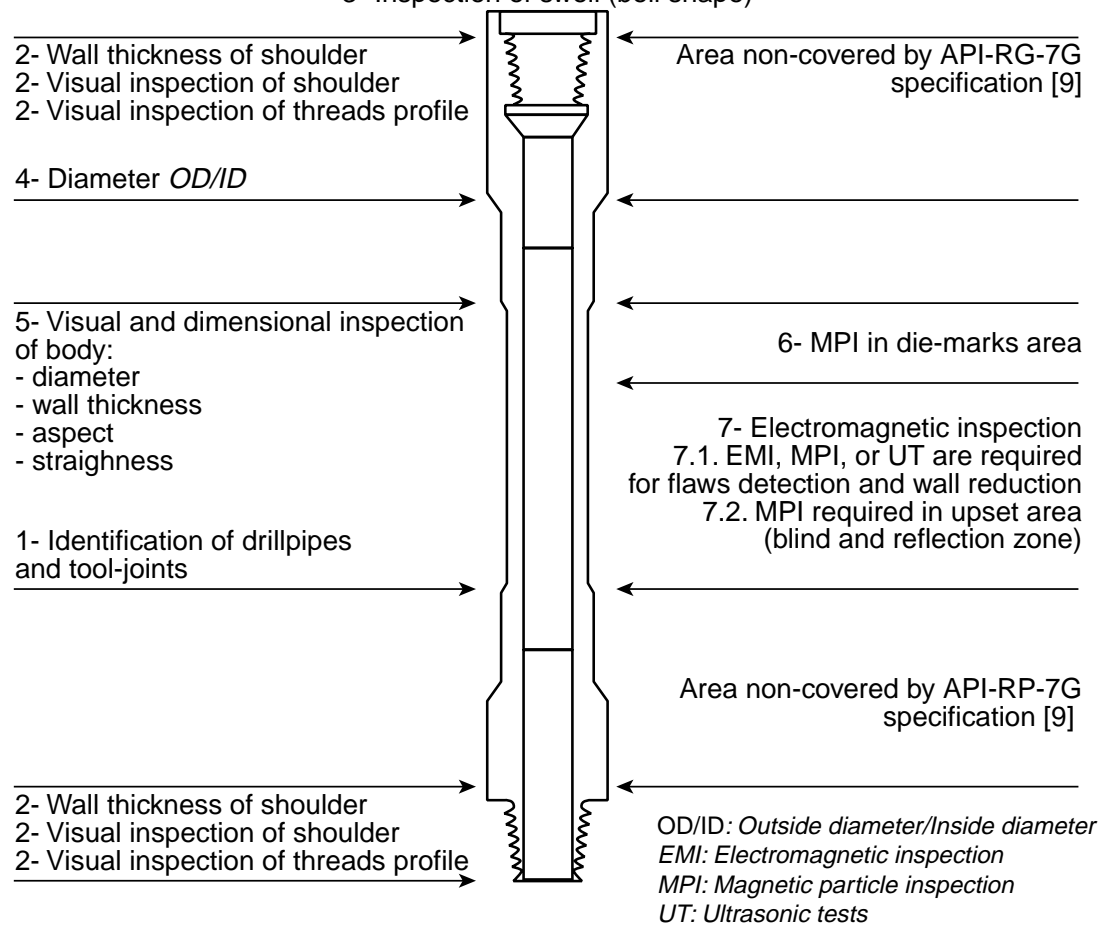

Figure 17

Inspection recommended according to "API-RP-7G".

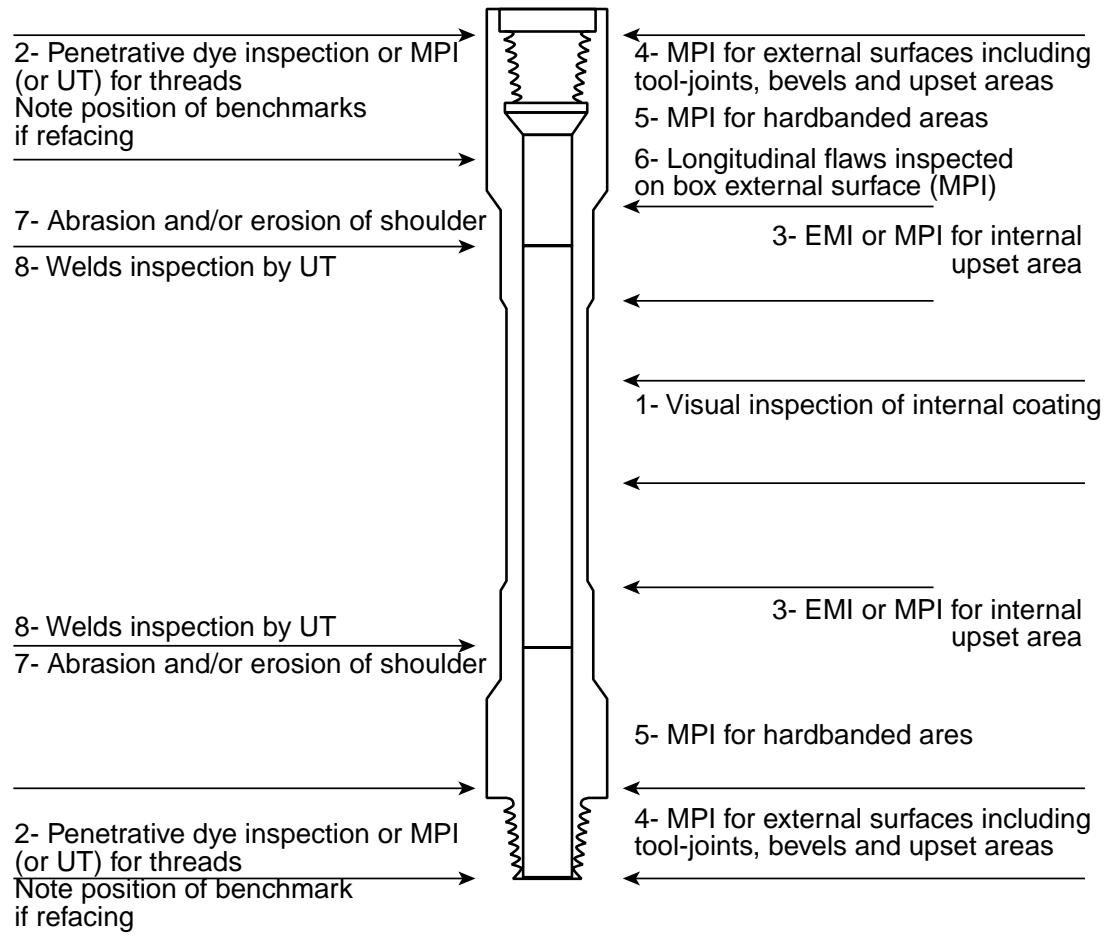

Figure 18

Optional inspection recommended. 
criteria. Therefore, he specifies inspection apparatus, preparation of drillpipes, calibration, standardization and inspection procedure. The inspector is responsible to examine each piece listed in strict compliance with the processes. The inspector accepts or rejects each piece based on whether its attributes meet the customer's acceptance criteria. All the results must be communicated.

A partly inspection is not recommended but if decided, a representative sample should be selected and an acceptable reject rate should be stated.

\subsection{Methods and Specifications}

Specific characteristics of drillstring inspection methods are pointed out by Kahil [35]. The inspection of tubular strings is clearly divided into new pipe inspection, aimed at the detection of manufacturing defects, and used pipe inspection, aimed at the detection of service induced defects.

The most common defects found in new pipe are tight spiraling seams, jagged overlaps and slug-pits of irregular shape. Wall thickness is not said to be a major problem. As the surface is generally smooth and free of scale, contact inspection apparatus can be used.

New component specifications widely used are for example SQAIR (Shell Quality And Inspection Requirements), NORSOK (North Sea recommendations; note that NORSOK was closed down the 7th June 2000 following a decision made by $O L F$ and TBL Offshore the 25th February 2000), “API Specification 5D" [36] (for tubes and upset definition), "API-RP-7G" [9] (for drill collar and tool-joints definition) for acceptance criteria and "API-RP-5A5" [37] for inspection procedure. However, API does not address any specification for heavy weight drillpipes, jars, motors, underreamers, hole openers, kellys, subs, stabilizers, etc. Table 2 lists some important properties of drillstring components [33]. Table 3 recalls the properties covered by API specifications, as per [33].

The most common defects in used pipes depend on the application. Usually corrosion pits, transverse fatigue cracks, starting cracks, holes, diameter reduction and nonstandard dimensions can be detected. Due to high service loads or remachining, drillstring dimensions can be changed in diameter, in tool-joint length, in taper (pin length or box depth), in bevels diameter or in wrench bearing. The surface of used pipes is generally rough because of corrosion and mechanical damage, and is often covered with scale, mud, paraffin and other contaminants. Therefore, cleaning must be planned and contact probes should be used with care.

Existing specifications for used component are "API-RP7G" [9] for acceptance criteria and "Standard DS-1" [32] for inspection process quality control.

The acceptance criteria are broken down in three drillpipe classes: Class 1 or new pipe, Premium Class or 80-percent as strong in tension and torsion as nominal new drillpipe with standard sized tool-joints, Class 2 drillpipe or 70-percent as strong in tension and torsion as nominal new drillpipe with standard sized tool-joints. Hill [32] has added another class (i.e. Premium Class with reduced torsion strength ratio) which recognizes long-standing industry practice of using smaller tool-joints outside diameter to gain better fishing clearance (see Table 4 for further details). When "API-RP7G" [9] was first issued, Class 3 and Class 4 were considered usable in many circles, but by now they are considered too worn for most needs.

Many inspection methods are available, their characteristics are compared in Table 5 as per Hill [31]. Only ultrasonic and electromagnetic methods will be mainly described hereunder. Anyway, visual inspection should always be performed for all inspections.

TABLE 2

Important properties in drillstring components (as per Shell Expro and Exxon [33])

\begin{tabular}{l|l}
\hline Properties & Why this is important \\
\hline Minimum yield strength & $\begin{array}{l}\text { Determines minimum rated capacity in torsion, tension, burst and collapse pressure for a given } \\
\text { component size }\end{array}$ \\
\hline Minimum tensile strength & Determines parting load in torsion, tension, burst and collapse for a given component size \\
\hline Maximum yield strength & Helps ensure that material is not too hard and brittle \\
\hline Minimum ductility & Ensures a minimum amount of plastic stretch after yield but before parting \\
\hline Minimum toughness & $\begin{array}{l}\text { Ensures a minimum resistance to fatigue crack extension. Ensures that a component can support } \\
\text { at least a through wall crack without parting (leak before break) }\end{array}$ \\
\hline Internal upset geometry & $\begin{array}{l}\text { Determines the stress concentration effect of the change in wall section at the internal upset on a } \\
\text { drillpipe tube. This in turn affects the fatigue life of the tube (higher stress and then shorter life) }\end{array}$ \\
\hline
\end{tabular}


TABLE 3

Properties covered by API Specifications (as per Shell Expro and Exxon [33])

\begin{tabular}{|c|c|c|c|}
\hline Component & $\begin{array}{l}\text { Yield strength, tensile strength, } \\
\text { ductility }\end{array}$ & Toughness & Internal upset geometry \\
\hline Drillpipe tubes & Specification 5D & Specification 5D & Specification 5D, Grade E only \\
\hline Tool-joints & Specification 7 & Not covered & Does not apply \\
\hline Drill collars & Specification 7 & Not covered & Does not apply \\
\hline Subs, Kellys & Specification 7 & Not covered & Does not apply \\
\hline $\operatorname{HWDP}^{(1)}$ & Not covered & Not covered & Does not apply \\
\hline Stabilizers & Not covered & Not covered & Does not apply \\
\hline Motors, MWD ${ }^{(2)}$ & Not covered & Not covered & Does not apply \\
\hline $\begin{array}{l}\text { Jar, hole openers, under } \\
\text { reamers, shock subs }\end{array}$ & Not covered & Not covered & Does not apply \\
\hline $\begin{array}{l}\text { Kelly valves, safety valves, } \\
\text { BOP's }^{(3)}\end{array}$ & Not covered & Not covered & Does not apply \\
\hline
\end{tabular}

(1) HWDP is heavy weight drillpipe.

(2) MWD is measurement while drilling system.

(3) BOP is blow out preventer.

TABLE 4

Classification of used drillpipe tubes and tool-joints

\begin{tabular}{|c|c|c|c|}
\hline Condition & Premium Class & $\begin{array}{l}\text { Premium Class } \\
\text { Reduced tensile } \\
\text { Strength ratio }\end{array}$ & Class 2 \\
\hline $\begin{array}{l}\text { Tubes } \\
\text { Minimum remaining wall } \\
\text { thickness } \\
\text { Slip cuts and gouges }{ }^{(2)} \\
\text { (Depth) } \\
\text { Diameter reduction } \\
\text { Diameter increase } \\
\text { Cracks }\end{array}$ & $\begin{array}{l}\geq 80 \% \\
\leq 10 \% \text { of average adjacent wall }{ }^{(3)} \\
\leq 3 \% \text { of specified } \mathrm{OD}^{(4)} \\
\leq 3 \% \text { of specified } \mathrm{OD}^{(4)} \\
\text { None }\end{array}$ & $\begin{array}{l}\geq 80 \% \\
\leq 10 \% \text { of average adjacent wall }{ }^{(3)} \\
\text { Not specified } \\
\text { Not specified } \\
\text { None }\end{array}$ & $\begin{array}{l}\geq 70 \% \\
\leq 20 \% \text { of average adjacent wall }{ }^{(1)} \\
\leq 4 \% \text { of specified } \mathrm{OD}^{(4)} \\
\leq 4 \% \text { of specified } \mathrm{OD}^{(4)} \\
\text { None }\end{array}$ \\
\hline $\begin{array}{l}\text { Tool-joints } \\
\text { Torsional strength }\end{array}$ & $\geq 80 \%$ of a Premium Class tube & $\begin{array}{l}60-80 \% \text { of a Premium Class } \\
\text { reduced } \mathrm{TSR}^{(5)} \text { tube }\end{array}$ & $\geq 80 \%$ of a Class 2 tube \\
\hline $\begin{array}{l}\text { Pin stretch } \\
\text { Cracks }\end{array}$ & $\begin{array}{l}\leq 0.006^{\prime \prime} \text { in } 2^{\prime \prime}(6) \\
\text { None }\end{array}$ & $\begin{array}{l}\text { Not specified } \\
\text { None }\end{array}$ & $\begin{array}{l}\leq 0.006^{\prime \prime} \text { in } 2^{\prime \prime(6)} \\
\text { None }\end{array}$ \\
\hline
\end{tabular}

(1) Minimum remaining wall thickness must be $\geq 80 \%$ under transverse cuts and gouges.

(2) Cuts and gouges may be removed by grinding provided the remaining wall is not reduced below the minimum remaining wall shown in this table.

(3) Average adjacent wall is determined by averaging the wall thickness on each side of the imperfection adjacent to the deepest penetration.

(4) OD is outside diameter.

(5) TSR is tensile strength ratio.

(6) $\leq 0.006 "$ in $2 "$ is equivalent to $\leq 0.1524 \mathrm{~mm}$ in $50.8 \mathrm{~mm}$. 
TABLE 5

Common inspection methods for used drillpipes and $\mathrm{BHA}^{(3)}$ components (as per Hill [31])

\begin{tabular}{|c|c|c|}
\hline Drillpipe tube bodies & $\begin{array}{l}\text { Electromagnetic inspection } \\
\text { Ultrasonic wall thickness } \\
\mathrm{OD}^{(1)} \text { gauging } \\
\text { Visual } \\
\text { Dry magnetic particle inspection }\left(\mathrm{MPI}^{(2)}\right) \\
\text { of end areas } \\
\text { Electronic end area inspection }\end{array}$ & $\begin{array}{l}\text { Fatigue cracks, corrosion pits, mechanical damage } \\
\text { Wall reduction } \\
\text { OD } \\
\text { Mechanical damage } \\
\text { Fatigue cracks in end areas } \\
\text { Fatigue cracks, corrosion pits, mechanical damage } \\
\text { in end areas }\end{array}$ \\
\hline Drillpipe tool-joints & $\begin{array}{l}\text { Visual } \\
\text { Dimensional } \\
\text { Wet magnetic particle inspection }\left(\mathrm{MPI}^{(2)}\right)\end{array}$ & $\begin{array}{l}\text { Mechanical damage, weight/grade identification } \\
\text { Mechanical damage, wear } \\
\text { Fatigue cracks in threads }\end{array}$ \\
\hline $\begin{array}{l}\text { Rotary shouldered connections on } \\
\text { drill collars and } \mathrm{BHA}^{(3)} \text { components }\end{array}$ & $\begin{array}{l}\text { Visual } \\
\text { Dimensional } \\
\text { Wet magnetic particle inspection }\left(\mathrm{MPI}^{(2)}\right) \\
\text { Ultrasonic inspection }\end{array}$ & $\begin{array}{l}\text { Mechanical damage } \\
\text { Mechanical damage, wear, inadequate } \mathrm{BSR}^{(4)} \\
\text { Fatigue cracks in threads } \\
\text { Fatigue cracks in threads }\end{array}$ \\
\hline Floor safety valves inside BOP's ${ }^{(5)}$ & $\begin{array}{l}\text { Disassembly and visual } \\
\text { Hydrotest } \\
\text { Wet MPI internal threads }\end{array}$ & $\begin{array}{l}\text { Improper components, worn or damaged components } \\
\text { Leaks } \\
\text { Fatigue cracks }\end{array}$ \\
\hline
\end{tabular}

(1) OD is outside diameter.

(2) MPI is magnetic particle inspection.

(3) BHA is bottom hole assembly.

(4) BSR is bending strength ratio.

(5) BOP is blow out preventer.

\subsection{Visual Inspection}

Naked-eye examinations can detect gross fatigue cracks and thread damage, particularly with the aid of a profile gauge. However, they may not detect the discontinuities. Therefore, inspection should not be limited to a visual examination.

Visual inspection is required for internal and external surface inspection of drillpipe tubes. Surface imperfections and coating wears should be notified. Crooked pipe must be rejected. Pipe outside diameter can also be inspected using an OD gauge, (note that OD is outside diameter). Accuracy is close to \pm 0.002 inch $( \pm 0.0508 \mathrm{~mm})$ [32].

Upset external surface, seal, threads, hardfacing, bevel, box swell, box shoulder width, pin stretch, tong space, shoulder flatness, etc., should be visually inspected.

Regarding refacing of pin or box threads, their pitch diameter should be equal in order to avoid any thread interference and subsequent leaks. API refacing benchmarks show the position of the original shoulder, so the inspector can determine if too much refacing has occurred. An audit of local machine shop facilities including equipment and skilled personnel should be made to determine the availability of qualified service [34].

\subsection{Electromagnetic Inspection}

Electromagnetic methods are widely employed as they can be used in different ways.
Electromagnetic inspection (EMI) is a widespread method used to locate three-dimensional flaws. The system could be made up of a motorized drive unit which has an inspection head scanner. The head is encircled by a strong active field DC (direct current) electromagnet. As the drive unit moves along the length of the tubular, the head sends signals from suspected defect locations back to the chart recorder where they are displayed graphically. Upon passing over a discontinuity in the induced magnetic flux path, a wire search coil may be excited with a voltage in any of eight shoes located in the head.

However, the search coils have a great sensitivity to speed changes, they have a dead point at the ends and the output signal is nonlinear. Erroneous signals may be received due to abrupt changes in wall thickness at the transition area. Wade Edens [38] proposes to improve the latest method by using a solid state sensor and its associated electronics packaged in integrated circuit chips.

Shaffer [39] thinks that EMI is not reliable enough as further prove-up is typically necessary, for example by using magnetic particle application.

The Wellhead Scanalog described by Kahil from Baker Hugues Tubular Services [35] is a computerized system for the inspection of used tubing at the wellhead during a trip.

Corrosion pitting are detected and measured by a magnetic method: the magnetization of the pipe is provided by stationary coil arrays distributed around the pipe and driven by computer-controlled currents in order to produce a 
rotating magnetic field. Signal detection is provided by separate stationary coil arrays and it is based on magnetic flux leakage method.

A low-frequency eddy-current scan is added for the detection and identification of full-penetration holes and splits.

The cross-sectional area of the pipe and therefore the wall thickness is measured by using a new magnetic flux density method.

However, detection threshold, which is not provided in Paper [35], might be higher than the crack initiation size. This inspection method is essentially based on a wall thickness measurement.

The MPI (wet fluorescent magnetic particle or black-light inspection) is conducted by Hill [31] to detect transverse surface flaws in tool-joints. Magnetic flux, created by a DC coil, an AC (alternating current) coil or an AC yoke, leaks out in the presence of a sharp geometric discontinuity, e.g. a fatigue crack. This flux leakage attracts and holds soft iron particle suspended in a liquid carrier and poured or sprayed onto the test piece. The iron particles are coated with a fluorescent material that shines brightly when the surface is viewed under ultraviolet or black light.

An expert should conduct this method because results are dependent on the strength of the field (flux density), on particle concentration and on black-light intensity. An active field method is therefore recommended. As described in Section 3.5 (item 1), this method can also be performed for crack detection on small-scale test specimen.

Penetrative dye inspection [40] is used to examine connections that cannot be inspected with MPI. Like in magnetic particle methods, a dye carrying liquid is applied to the surface and allowed to penetrate surface discontinuities. After removal of excess remaining fluid, a developer blotting powder is applied. Visible indications are drawn when the penetrating fluid moves out of defaults. This inspection is an expert-method mostly used for surface flaws detection in nonmagnetic BHA tool-joints.

Moreover, the penetrative methods are slow processes that require more than $30 \mathrm{~min}$ for a complete penetration of the fluid. Smooth and clean surface is required. Discontinuities require to be open to the surface to be detectable, but the best resolution is close to $0.005 \mathrm{inch}(0.127 \mathrm{~mm})$ [41].

\subsection{Ultrasonic Inspection}

Ultrasonic inspection is mentioned by Stanley [42] as a more accurate method than MPI. Anyway, it is mainly based on a wall thickness measurement.

In the piezoelectric technology, widely employed for its efficiency in ultrasonic, ultra sound is generated by a ferroelectric ceramic which transforms electrical energy in mechanical energy. This sound is fired in the material via a thin coupling fluid such as oil or water based liquid.
One of the following ultrasonic methods presented hereunder is performed using a contact sensor [40, 41]. Transverse fatigue cracks may be detected in the critical areas of the drillpipe tube with a shear wave ultrasonic system that fires sound toward the upset region. It detects sound reflected from imperfections. Time to cover the distance between receiver and transmitter heads is measured; it is directly proportional to the wall thickness. Flaws are detected by an array of several transducers with sound beams overlapping. Detection of a notch approximately 0.1 inch ( $2.54 \mathrm{~mm}$ ) deep is the best sensitivity obtainable. Horbeek [33] reports that the main difference in cost between "APIRP-7G" [9] and the Shell Expro Drillstring Inspection Specification was the ultrasonic inspection of the drillpipe upset area with an increased average cost of $£ 11.20$ per joint of drillstring inspected. "API-RP-7G" [9] does not address this type of inspection in this critical area, where the majority of drillpipe fatigue failures may occur.

Regarding probe selection [40], a high frequency transducer, e.g. $5 \mathrm{MHz}$, provides better resolution, but attenuation and noise limit its penetration. Frequency below $2.25 \mathrm{MHz}$ may not provide enough resolution. For a given frequency, a large probe diameter gives less beam spread and better penetration of the material, but sacrifices some resolution. The most useful probes appear to be those with diameters between 0.25 inch and 0.5 inch (between $6.35 \mathrm{~mm}$ and $12.7 \mathrm{~mm}$ ) with frequencies of 2.25 or $5 \mathrm{MHz}$. Surface condition such as machining grooves, galling and stabbing damage or corrosion, pits and gouges can increase the scatter of results and make coupling difficult. Probe orientation also greatly affects the sensitivity. Thus, specialized equipment and highly trained personnel are required.

Stanley [42] proposes another version of ultrasonic measurement dedicated for crack inspection in threaded box connections. The use of a 4-degree wedge allows compression wave ultrasound of frequency around $10 \mathrm{MHz}$ to enter the ends of a shouldered connection at a suitable angle for directing the beam along the roots of the threads. The reflections should be observed on an appropriate screen so that the sound reaches the last threads, and small indications at regular intervals can be seen from ultrasound diffracted from each thread.

Another ultrasonic inspection available is a noncontactsensor method as described in [43]. Regarding benefit, no coupling-fluid is required and surface to be inspected can be quite rough. The ultra sonic imager tool (USIT) was introduced by Ananto to evaluate the quality of the cement around the casing and at the same time measure the internal radius and the thickness of the casing, even when the casing is not round or inside high-deviated wellbore. Oil or water base mud is necessary as it is a transmission liquid. These measurements are performed in five-degree increments around the casing. The transducer located in the rotating head, spins at 6.5 to 7.5 revolutions per second. The 
maximum vertical resolution of the measurement is 2 inches $(50.8 \mathrm{~mm})$. However, this method may not be accurate enough for fatigue crack detection, as it was not developed for such a use.

In order to avoid any coupling fluid as well as contactsensor, the Centre technique des industries mécaniques (CETIM) [44] has developed an electromagnetic-ultrasonic inspection method, called EMAT. Impulsive and highintensity eddy currents are generated by a coil in the steel. A Lorentz's force is created from interaction between these eddy currents and a magnetic field created by permanent magnets. This Lorentz's force is directly applied to the current lines and then is transmitted to the material atoms by ultra sounds. Generated sounds propagate through material and perturbed echoes are measured in the same way. Frequency is $2.5 \mathrm{MHz}$. However, this interesting method has not been conducted yet in field and may be adapted for drilling inspection environment.

It is important to note that a reference standard is needed to calibrate the ultrasonic instruments for distance and sensitivity.

As a conclusion, some standardization of existing inspection procedures in the industry is necessary as consistency and repeatability of inspection results is to be achieved. Nevertheless, some other inspection methods may be investigated as they may enhance the existing procedures.

\subsection{Q uality and Frequency of Inspection Methods}

Conventional inspection methods as already described allow detection of only macroscopic cracks. Many referenced papers confirm this. Propagation of fatigue cracks, which represents a few percent of the remaining life before failure, is the only detectable step.

As per Dale [45], electromagnetic inspection method applied on drillpipe body has a probability of detection (POD) of 90-percent providing that crack depth is larger than 0.039 inch $(1 \mathrm{~mm})$. POD is close to 99-percent when minimum crack depth is 0.049 inch $(1.25 \mathrm{~mm})$. These figures are not available for tool-joint inspection. POD represents the combined effects of inspection methodology, human factors, equipment variability and measurement repeatability.

Magnetic-particle inspection mainly applied for connection inspection has a probability of detection of only 40-percent. This method is highly dependent on the way the inspection procedure is carried out and how the inspector operates. For example [46], a Linalog service inspector will spend two to three years in training, in the field or in the classroom, before taking up a supervisory or advisory role. Unfortunately, most of the fatigue failures occur in the tool-joints area.

Based on these results, Dale proposes the following example on the pipe body inspection [45]. If three inspections are planned during life duration of a drillpipe, probability of detection of cracks in body is 90-percent. If six inspections are performed, POD increases to 99-percent.

This probability of detection figure is available for only one pipe. Probability of failure (POF) of the whole drillstring, assuming $n$ pipes, is given by (24).

$$
1-\mathrm{POF}=(1-\mathrm{POD})^{n}
$$

Therefore, existing standard inspection methods are far from a high-reliable required method (e.g. POD of 99.9percent).

Drillpipes should be inspected regularly in service life, e.g. standard figures at every 200 to 300 rotating hours is reported in [41, 47] for entire bottom hole assembly, including the first 20 drillpipes, every 1500 rotating hours for the remaining drillpipes. For bottom hole assembly run in extended reach wells, Yoder [48] recommends to increase inspection frequency to a minimum of 150 rotating hours.

Life duration may be divided roughly in two stages: incubation plus initiation of microscopic cracks is the first stage, flaws are however considered undetectable. Second step is the propagation of a macroscopic crack. Detection is available but propagation duration is dramatically shorter than initiation. Frequency of inspection should be planned periodically using the cumulative fatigue calculations, the fatigue crack growth rates, the probability of crack detection and the engineering statistics, but must include the drilling field limitations [33].

Formulae are existing to calculate life duration [45], e.g. (25) where fatigue crack propagation may be expressed as a function of cyclic bending stress $\sigma_{b}$, outside diameter $D$, crack plane diameter $d_{c}$, and fatigue constants $F_{0}$ and $n$, depending on steel characteristics (typically $7.2510^{5}<F_{0}$ $\left.<1.3510^{6}, 2.52<n<2.94\right)$.

$$
N=\left[\frac{F_{0}}{\sigma_{b}}\left(\frac{D}{d_{c}}\right)\right]^{n}
$$

Ligrone [47] has issued a tool to estimate the performance of a given drillstem with small set of data. It is based on Blom's algorithm, see (26), which gives the decrease estimation of the probability of success of an item $i$ with time.

$$
R\left(t_{i}\right)=\frac{n-i+0.625}{n+0.25}
$$

where $R$ is a reliability estimator and we suppose a small set of $n$ failures occurred at certain time $t_{i}$. For each drillstring component, a reliability threshold that can be met with proper tuning of the non-destructive tests has been established.

Hill has reported [4] that many of the inspection failures experienced in the field are not caused by technical limitations but are the consequence of the poor application of 
the methods. The inspection contractor frequently operates in a conflict of interest environment.

Ligrone [47] reports an interesting example of failures and lost time per well with and without nondestructive tests (Table 6).

TABLE 6

Failures and lost time per well (as per Agip [47])

\begin{tabular}{l|c|c|c}
\hline & $\begin{array}{c}\text { Failure } \\
\text { in well }\end{array}$ & $\begin{array}{c}\text { Lost time } \\
\text { (day) }\end{array}$ & $\begin{array}{c}\text { Cost due to drilling } \\
\text { failure, considering } \\
\text { only rig lost time } \\
\text { (US\$) }\end{array}$ \\
\hline $\begin{array}{l}\text { Without NDT } \\
\text { With } \mathrm{NDT}^{(1)} \text { inspection }\end{array}$ & 5.9 & 17.6 & 370000 \\
4.3 & $80000+170000$ \\
for inspections
\end{tabular}

(1) NDT is nondestructive tests.

Due to the low reliability of the existing inspection methods and the lack of standard recommendations, we do believe that the field is still open to improvement.

\subsection{Flaws Detected}

Any nonstandard geometric length or shape must be reported because drillpipes may have been use in abnormal conditions such as high loads. Direct consequences will be the growth of cracks and then failure.

Hill [31] has reported the following failure causes:

- Fatigue cracks in high-stress areas of connections and drillpipe tubes, mainly perpendicular to the threads root. Appearance is often a flat crack, perpendicular to the pipe axis.

- Washouts caused by leaking mud. Drilling mud can erode and enlarge the leak.

- Tensile breaks.

- Torsional failures. Tension and torsion failures can often yield 45-degree cracks.

As introduced in the first section and in reference [4], fatigue is the main cause of failure in 77-percent. Torsion breaks due to fatigue is 43-percent.

Most of the time, damage of drillpipe such as cracking, blistering, corrosion and loss in wall thickness occurs at the same time when internal coating is worn. Gensmer [49] has reported that metal fatigue cracks are locally destroying the coating. As the coating is gone, crevice corrosion and erosion attacks are easily accelerated. Stress corrosion phenomenon is described in paper [50]. Fatigue cracks often rise from corrosion pitting and increase when applying downhole stresses such as rotation, bending, pressure, heat and the corrosive environment.

Many authors agree that most of the time fatigue failures take place in the end areas where, because of the strength built into drillpipes tool-joints and upset areas, the adjacent tube body is more susceptible to the rotary stresses of drilling.

A statistical analysis given in [51] notifies that failures are located in the $920 \mathrm{~mm}$-area from the box or pin ends. Anyway, most of the failures are in a zone between $250 \mathrm{~mm}$ and $640 \mathrm{~mm}$ from the ends.

Failures initiated from threads are often reported. Based in the latest statistical analysis [4], areas are located between 0 and $120 \mathrm{~mm}$ from the ends. However, the number of thread failures is lower than the nonthreads failures.

As a conclusion of this section, geometrical defaults are always involved in fatigue failure. Geometrical defects can be summarized as follows:

- Length of tool-joints may be modified by remachining.

- Tool-joints geometry: bevel length must be larger than API recommendations, bevel diameter should not be to strong when remachining, length for wrench must be adapted, die-marks of gripping system must be minimized. Some companies discard drillpipes when die-mark depth is higher than 0.02 inch to 0.0315 inch (0.5 $\mathrm{mm}$ to $0.8 \mathrm{~mm})$.

- Tool-joint inside geometry: diameter reduction should be carried out with a conical profile with a minimum length of 0.492 inch $(12.5 \mathrm{~mm})$.

- Tensile residual stresses when tool-joint is welded on pipe body could be the location of fatigue cracks [42]. Grinding and heating are cheap and easy solutions if correctly applied.

\section{FATIGUE TESTS}

\subsection{General}

In conditions where human life and the environment may be at risk, equipment is usually tested in laboratory under dynamic and static load conditions. Fatigue tests are recommended to better understand material characteristics as well as to reflect downhole conditions, which may cause damage. They are one of the first steps for modelisation of both cumulative fatigue damage and fracture approaches. The main aspects to be considered are the loading conditions, the test frequency and the number and the size of test specimens.

Static load test results are usually compared to the mechanical characteristics guaranteed by the manufacturer and in practice failures due to static loads are quite rare. However, strength in dynamic load conditions is not studied in depth and therefore fatigue test should be carried out.

Fatigue test results obtained under controlled load conditions are used to define the familiar fatigue $S-N$ curve. For tools that do not have an asymptote towards horizontal (endurance limit) in the $S-N$ curve, the fatigue limit is usually 
chosen as the load amplitude corresponding to a life of $10^{7}$ cycles for steel and $2.10^{7}$ cycles for nonferrous metals [19]. These figures are the minimum number of cycles recommended by Baryshnikov as a basis for fatigue tests for downhole equipment. Sometimes full-scale comparative fatigue tests are carried out without obtaining the fatigue limits. These results are interesting only if the dynamic load level corresponds to an actual downhole dynamic load condition.

\subsection{Nature of the Different Tests}

Three types of fatigue tests are usually conducted:

- Cyclic axial tension tests are performed on a servohydraulic test machine (Fig. 19). This had a built-in load cell connected to the servo-control loop, which maintained constant amplitude loading, regardless of the axial displacement. Load, displacement or strain should be servo-hydraulic computer-controlled $[6,52,53]$ using any cycle shapes such as ramp, sinus, square signal, etc. Quality control must be focused on specimen endmounting, alignment of gripping system, calibration of cells and PID (pipe internal diameter). When specimen stiffness may change during test, algorithm including adaptive PID must be carried out in order to balance load offset.

- Simple bending fatigue tests are described by Grondin [54]. Specimens are tested in flexure using a span with two-point loading in the central portion of the span. A servo-hydraulic jack applies fluctuating loads on the loading points via a distributing beam. Load is cycled such that the stress at the bottom fiber of the specimen in the constant moment region varied from maximum to minimum tension. A superimposed static axial load can also be applied to simulate the weight of the drillstring at a dogleg.

- Rotating bending tests with or without axial tensile loads are also available in $[1,2,21,52]$. See Figure 20 for further details. On a four-point bending situation, hydraulic jacks applied constant loads on the center of the string creating a permanent deflection and thus bending loads. One end mounting is structurally fixed. An axial load can be added if wanted. A variable frequency electric motor is connected to the other end to provide fully reversed cyclic stressing of the stem. Pipe body should be instrumented with load cells and strain gauges as well.

Regarding full-scale fatigue tests on connections, Baryshnikov [55] reports an interesting case history where he discusses the experience of downhole tool full-scale fatigue tests published since 1950. A lack of requirements for fatigue tests in existing specifications causes significant dispersion of the results and no database is available.

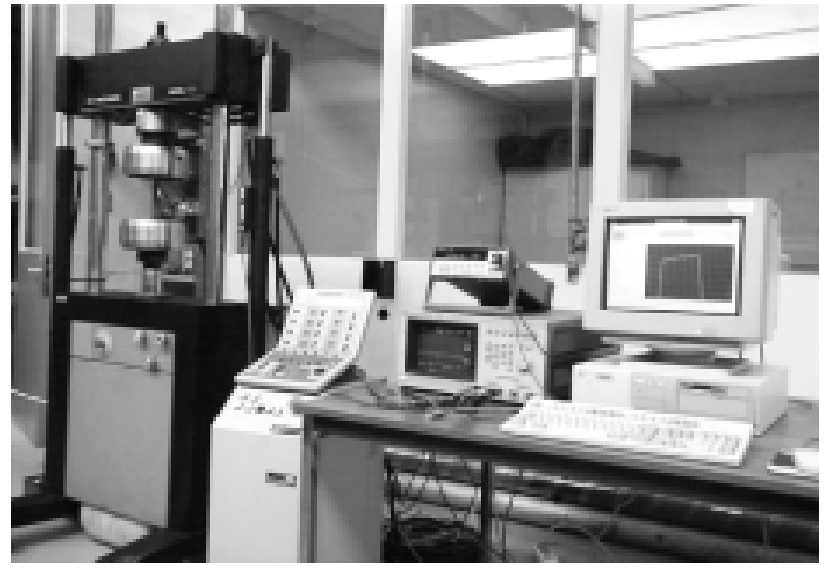

Figure 19

Fatigue testing machine (compressive and tensile loads).

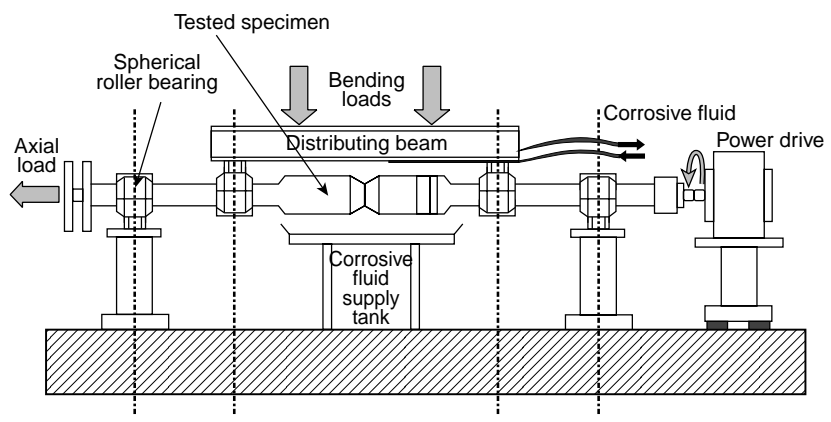

Figure 20

Rotating bending test set-up.

\subsection{Specimens Size}

Many papers refer to full-scale tests [1, 2, 19, 21, 52, 54-56]. To obtain a better simulation of field operating conditions, full-size fatigue tests should be conducted. No scale effects intercede with the results providing that applied loads reflect drillpipe stresses encountered in wellbore. Specimens can be easily prepared so that the whole tool-joint, upset region and part of the pipe body could be included in the test. High stress areas, discontinuities, microscopic characteristics of steel (e.g. inclusion and grain sizes) as well as tensile axial loads are accurately represented at full size. However, specific testing rig must be created.

Tests on samples at reduced scale are sufficient to obtain material characteristics such as $S-N$ curves and endurance limits $[6,56]$. These specimens can be easily machined providing that shape, dimensions and manufacturing procedures are respected, e.g. as per [6]. Moreover, standard testing machines are widely available on the market. 
For $S-N$ curves determination, specimens should be cylindrical and have toroïdal profile [6]. Final machining is a longitudinal and fine adjusting. Specimen heat is hence easily removable and failure is located in the calibrated area.

It is worth to mention that fatigue $S-N$ curves are not meant to be a definite line but the average of a band obtained from the scatter of a large number of plotted points. This band is broad at the upper left where the stress loads are high and tapers downward in a curved fashion to a narrow band at the right part of the diagram at the fatigue endurance level.

For oligocyclic fatigue, parameters of elastoplastic material laws can also be fitted from small-scale sample tests conducted in constant strain amplitude for example.

This paper will not discuss in detail the geometry and the use of the notched specimens whereas they are widely employed for fatigue crack propagation tests. Crack lateral location coupons such as KT (tension test specimen), KF (bending test specimen), CT and RCT (compact tension test specimens) and crack central location coupons (CCT) are the most employed specimens [6] (see Figures 21 and 22 for further details on geometry). CT coupons are tested in corrosive environment by Gonzalez-Rodriguez [50] or Hatcher [53] because of space limitations in the autoclave. Crack root geometry is also important as crack initiation and propagation is shape dependent. Rafter shape is widely used. Prior to testing, the specimens should be abraded to a 600-grade emery finish and degreased with acetone [50].

\subsection{Frequency}

Test frequency at full-size should be from 0 to $7 \mathrm{~Hz}$ as the bending reversed stresses are a quite low frequency phenomenon [21].
Under corrosive environment, tests should be carried out at low frequency, lower than $1.5 \mathrm{~Hz}$, in order to have a better flow of the corrosive fluid in the crack root $[21,50,53]$. For frequency upper than $5 \mathrm{~Hz}$, corrosion effects should be neglected $[2,54]$. It is worth to mention that $\mathrm{pH}$ can be modified by $\mathrm{H}_{2} \mathrm{SO}_{4}$ (sulfuric acid) or $\mathrm{NaOH}$ (caustic soda) respectively for acid or basic adjustment in an autoclave nitrogen-pressurized brine environment [53].

At reduced scale, if specimen is not heated by itself and if testing machine is still reliable, frequency can be increased to $50 \mathrm{~Hz}$ in air and noncorrosive environment [6].

\subsection{Crack Detection and Propagation Measurement}

The main procedures conducted to detect cracks on tested specimens and monitor their propagation can be split into two sections: with or without precalibration. Some methods are common with those described in Section 2. Nonprecalibrated systems are the following:

- Magnetic particle inspection (MPI) or black light inspection is mostly used [40, 57] for carbon steel drillpipes inspection, but it can be easily conducted to detect and monitor cracks on full-scale specimens. In this process, the component is magnetized and sprayed with a medium containing magnetic particles in suspension. These particles move preferentially on surface defects. Under an UV light, the surface breaks can be seen as bright lines. Therefore, surface should be polished and cleaned as close to bright metal as possible. Regarding the drawbacks, the process detects only surface defaults and hence no depth can be measured except with grinding. Fatigue cracks almost invariably began at the root of the grooves introduced by grinding when these marks were

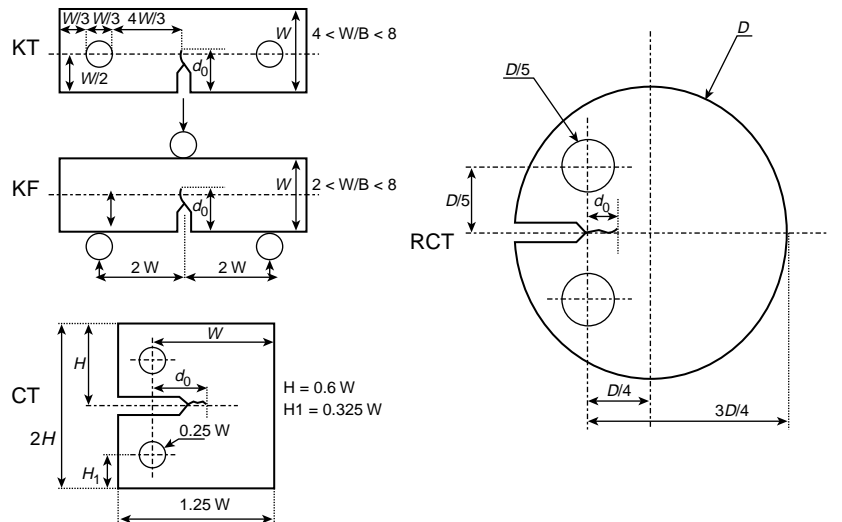

Figure 21

Lateral crack small-size specimens (as per [6]).

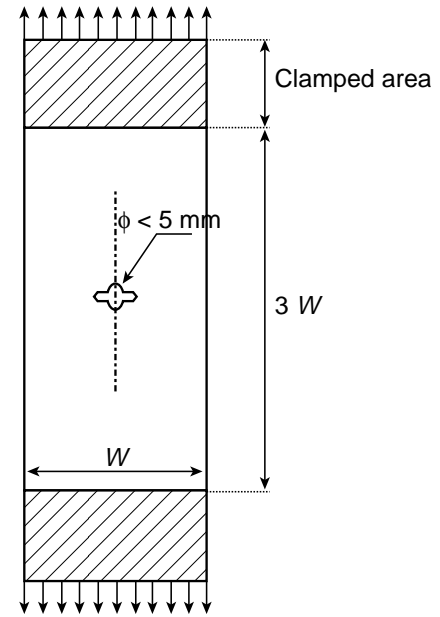

Figure 22

Central crack small-size specimen (as per [6]). 
oriented transverse to the direction of loading [21]. Therefore, surface grinding was found to introduce a notch effect and modifies residual stresses in the surface layer. Moreover, accessibility can be a major problem, e.g. when cracks are monitored in box connection.

- Optical measurement such as magnifying binocular system is recalled as it is one of the simplest devices. Magnifying ratio of 30 to 80 allows crack propagation measurement of $0.1 \mathrm{~mm}$ [6]. A calibrated grid microscope can be set up for visual inspection of compliance during the tests conducted in air [2].

- Eddy-currents are created in specimen using two coils mounted in a Wheatstone bridge. Perturbations of the signal induce a small displacement of the sensor along the crack and then measurement of surface crack propagation with an accuracy of $0.05 \mathrm{~mm}$. However, precision will be lost if material is said to be unstable or when striction of specimen is large enough (e.g. due to local plasticity in the crack root area) to induce a current decrease independently of crack propagation [6].

- Ladder-shape thin gauges mounted in parallel and bonded along the crack will progressively failed as soon as propagation occurs. Measurement is performed in surface and high velocity of propagation can be monitored (between 0.0001 and $1 \mathrm{~mm} /$ cycle for a $0.5 \mathrm{~mm}$ gauge interval) [6].

- Utrasonic wave measurement is based on the displacement of a $10 \mathrm{MHz}$ sensor. Precision is 0.01 to $0.03 \mathrm{~mm}$ [6].

Precalibrated systems are mainly based on current field measurements.

- Direct current (with intensity from 5 to $50 \mathrm{~A}$ ) or alternating current potential difference (e.g. square tension signal) have been in common use for offshore structure and aerospace inspection for several years. The methods are based on detection of anomalies in a current flow along a metal surface $[6,57]$.

- Alternating current field measurement (ACFM) has been recently conducted by Gaynor [57]. ACFM induced an electrical field on the metal surface of the component. If a perturbation is detected in the magnetic field created in the free space above the surface, a crack or defect is present. The severity of any break can be determined by measuring perturbations in the magnetic field. Length and depth can then be estimated.

Current field measurement methods allow monitoring of cracks in surface as well as in depth. Accuracy is about $0.05 \mathrm{~mm}$ for carbon steel. Moreover, system can be used on all metals, at any temperature.

ACFM does not require an experienced operator as it is recommended for MPI thread inspection [33].

- A gauge can be added to measure the crack mouth opening displacement (CMOD) especially for highstrength less-tensile steel [2, 6, 50, 53]. This CMOD gauge can be used for ambient tests in air as well as in pressurized environment such as in an autoclave system.
- Brennan [52] and Dale [2] have used beach-marking technique. It is based on fracture surface inspection. In order to determine the rate of fatigue crack growth, a procedure is used to generate marks on the fracture surface at prescribed intervals by employing cyclic load reductions. These beach marks recorded crack shape and position from which measurement and calculation of fatigue crack growth rate where made.

\subsection{Precraking Method}

In order to accelerate tests and reduce the time to initiate a fatigue crack, specimens should be cracked before starting the test.

Material can be precracked by a high electric shock, e.g. by an electric-discharge-machining (EDM) as used by Dale [2]. EDM has been used to produce a small starter notch in the thread roots of connections. This flaw serves as a crack initiation site and results in propagating fatigue crack at the beginning of each test.

Gonzalez-Rodriguez [50] has decided to precrack compact tension specimens in air at a frequency of $20 \mathrm{~Hz}$ with a sinusoidal waveform for the applied load using a closed-loop electro-hydraulic testing system. The compliance method was applied to find out the crack length as an empirical function of the applied load and the crack opening displacement. Applied load is measured by means of a load cell and the crack displacement with a clip gauge situated at the mouth of the specimen (CMOD gauge).

During the test, crack propagation velocity can be adjusted by frequency (from 1 to $150 \mathrm{~Hz}$ ) and applied load [6].

\subsection{O pen Literature Results}

Some fatigue test results at full size are recalled in $[52,55]$. Characteristics of steel tested are also mentioned in papers $[50,52,56]$.

\section{EN VIRO N MENT EFFECTS}

Corrosion probably plays a role in all drillstring fatigue failures. This section will list the environment effects and their consequence on the fatigue behavior of the drillstring. Prevention and mud inhibitors will be discussed.

\subsection{Corrosion Fatigue Factors}

Azar [58] has investigated drilling mud parameters that affect corrosion fatigue life. They are the following.

Dissolved oxygen is the main cause of drillpipe corrosion. As little as $3 \mathrm{ppm}$ dissolved oxygen cut fatigue life by as much as one-half compared with mud without dissolved oxygen. 
Increasing $\mathrm{CO}_{2}$ (carbon dioxide) concentration also reduces fatigue life but not as rapidly as increasing dissolved oxygen.

The $\mathrm{pH}$ has appreciable effects on fatigue life beyond a $\mathrm{pH}$ of 10.5. Anyway, mud $\mathrm{pH}$ control is necessary.

Jiashen [59] has reported rapid failure through hydrogen embrittlement in drilling muds containing $\mathrm{H}_{2} \mathrm{~S}$. Under the harmful action of $\mathrm{H}_{2} \mathrm{~S}$, hydrogen atoms diffuse easily into steel and accumulate as molecular hydrogen in voids on the interface of nonmetallic inclusion and matrices. By the action of stress, a mechanical crack initiates from the pit and propagates through the hydrogen-embrittled area. These microcracks tend to connect and form a continuous crack.

Gonzalez-Rodriguez [50] has studied influence of temperature, chlorides level and $\mathrm{pH}$ in water-based drilling mud. Moreover, he has tested specimens in zinc or copper environment: lubricants containing metallic zinc or copper are used to prevent galling of the threaded joints. Conclusions are the following. Increasing chloride concentration reduces fatigue life. The degree of susceptibility to corrosion fatigue increases with decreasing potential and $\mathrm{pH}$. With increasing temperature up to $80^{\circ} \mathrm{C}$ and addition of $\mathrm{Zn}$ containing dope ( $25 \%$ in weight), the crack growth rate is increased as well as the steady state hydrogen permeation current density. Similarly, the addition of $\mathrm{Cu}$-containing dope ( $25 \%$ in weight) decreases the value of hydrogen, and also decreases the crack propagation rate.

\subsection{Corrosion Effects}

Hill [4] reports at least two corrosion effects:

- corrosion accelerates the crack initiation phase by creating high stress areas;

- corrosion can accelerate the crack growth rate by attacking the newly exposed metal at the crack tip.

Moreover, corrosion reduces or eliminates the endurance limit of any $S$ - $N$ curves. The corrosion fatigue cracks seem to invariably start at the corroded interface between the $\mathrm{MnS}$ inclusions and the matrix [60] and then grow under the cyclic loads.

As already stated in Section 3.4, the lower is the frequency, the more are increased the corrosion effects.

$\mathrm{H}_{2} \mathrm{~S}$ (hydrogen sulfide) precursor effects were noticed by Hendrickson [61], which is in accordance with pipe exposure to hydrogen sulfide. One of these effects, only measured in laboratory tests, is a decrease in elastic stiffness of the pipe. The second effect reported is an increase in the bulk electrical resistance of specimens exposed to $\mathrm{H}_{2} \mathrm{~S}$.

\subsection{Prevention and Inhibitors}

Protection methods must be investigated in order to reduce the corrosion effects.
Enhancement of steel characteristics such as nitriding and nitrocarburizing thermochemical surface treatment, phosphatization, and oxidation treatment may delay the corrosion effects. Better chemistry, quenching and tempering to a low hardness would make steel more resistant to sulfide stress corrosion cracking and also more resistant to hydrogen embrittlement.

Nitrocarburizing involves the diffusional addition of both nitrogen and carbon to a steel surface at temperatures typically between $510^{\circ} \mathrm{C}$ and $590^{\circ} \mathrm{C}$, in gaseous and plasma atmospheres and in salt baths [60]. Additional improvements of wear resistance, fatigue strength and corrosion resistance are attributed to oxidation treatment at temperature below $570^{\circ} \mathrm{C}$ after the nitrocarburizing treatment, as per [60].

Because mean stresses are known to be an important factor in corrosive environment, compressive stresses applied on high stress concentration areas of drillpipes may restrain the crack propagation. These residual stresses can be applied mechanically by light grinding or polishing for example, but this partly reduces the corrosion resistance gained by the oxide layer. Nitriding and nitrocarburizing also lead to the formation of compressive residual stresses in the surface microstructure, moreover this compound layer acts as an anticorrosive coating.

Coating of both internal and external side of drillpipe may protect steel from corrosive and abrasive environment such as mud. A sacrificial cathode such as aluminum or zinc coating might diminish the potential difference and then increase the fatigue life despite the $\mathrm{H}^{+}$accumulation.

Double-shoulders connections may help to avoid any mud penetration in the thread roots.

Corrosion inhibitors and scavengers directly added in the mud are another way to improve the fatigue life. $\mathrm{pH}$ should be maintained at 10.5 or higher to help prevent corrosion [62]. Caustic soda should be used to control pH, not lime. Lime causes a scale to form on the drillpipe outside diameter, which causes corrosion [63]. Regarding $\mathrm{H}_{2} \mathrm{~S}$-containing mud, inhibitors, such as zinc oxide or zinc carbonate, suppress the hydrogen ion discharge reaction, which releases hydrogen atoms in the crack tip and then diffuses them into steel. The hydrogen sulfide concentration in the drilling mud should be monitored using a Garrett Gas Train as per "API-RP-13B” [64, 65]. Regarding polymer mud, $\mathrm{O}_{2}$ scavengers, such as catalyzed ammonium bisulfite, would reduce crack initiation and growth.

Chemical injection pumps designed for continuous treatment should be purchased and installed [34]. A batch mixing and storing reserve mud in a separate surface tank should be designed. Extra time is available to release air and foam before adding the mixture. The mud is then added to the active system without mixing additives and make-up water through the hopper system.

Another way to monitor and prevent corrosion effects is to insert small coupons inside the drillpipes and then 
to periodically check their shape. "API-RP-13B" [64, 65] provides information on the use of corrosion coupon rings.

When selecting mud, most of the drilling engineers focus on parameters that influence hole stability, penetration, well control and formation compatibility. To prevent fatigue, corrosion parameters must be highlighted on the list of mud design considerations.

Because corrosion can cause localized pitting on the pipe surfaces, which act as stress concentration areas and crack initiation sites, it is of major importance of monitoring and keeping drillpipe surfaces clear of these pits.

\section{HOW TO IMPROVE DRILLSTRIN G}

It is not the purpose to present herein new designs of drillstring or to present comparative tests on existing designs, although actual basic fatigue data on various designs seems to be lacking. Rather, it is intended to present information regarding possible methods of improvement which are applicable to almost any drillstem design. Section will be divided in five parts as follows. Firstly, drillpipe, drill collar and heavy weight drillpipe improvements will be listed. Next chapter will present how the connections may be enhanced as well as the characteristics of steel. Finally, classification and marking will be discussed.

\subsection{Drillpipe Improvement}

Drillpipes (DP) are engineered to work in tension, to transmit torque to the bit and to resist to internal pressure due to mud flow.

Regarding manufacturing of drillpipes, they are made of three parts. The pipe body is welded on the two threaded ends. Thickness of welded cross section is increased by forging because of the friction weld.

These forged sections and mainly the upset regions are highly loaded. Improvement in these areas are described in most of the paper and are discussed hereafter.

Many authors [49, 66-68] agree that the internal upset transition region of drillpipes is a singular area where stress concentration factors are the greatest. Figures 23 and 24 show the critical drillstring fatigue areas. The problem is amplified further by poor application of the internal plastic coating where corrosion protection is then lost.

Sweet [34] noticed that 93-percent of the drillpipes failures were near the ends of the pipe body, in the internal upset runout area. The failure distribution was 40-percent on the box and 60-percent on the pin end.

Noble Drilling [3, 49] recorded 18 premature failures in one drilling pipe string in the first 2800 rotating hours where normal life expectancy was $18000 \mathrm{~h}$. Most of the failed pipes had an internal taper upset length of less than one inch.

Geometry changes are recommended on the length of the upset region (Miu length i.e. minimum internal upset length) but also on the radius between the drillpipe inside diameter and the tapered portion of the offset. Based on finite element analyses and on full-scale fatigue tests (size tested is 5" pipe diameter, i.e. $127 \mathrm{~mm}$ pipe diameter), conclusion is to increase transition length and radius as much as possible. Upset design concept is based on the following: the maximum stress at any point in the bore of the pipe is less than the maximum stress at any point on the outside diameter. This insures that crack initiation will be on the outside surface, which is easier to detect with normal inspection methods. Stress concentration factor (SCF), which is the ratio of the inside maximum stress to the outside maximum stress, should be less than 1.0. These studies resulted in the adoption of a 2-inch $(50.8 \mathrm{~mm})$ minimum Miu length for Grade E 4 1/2-inch (114.3 mm), 16.60 livres/ft $(24.7 \mathrm{~kg} / \mathrm{m})$ drillpipe in "API Specification 5D” [36], in April 1989. No API recommendations are issued for the other grades. However, SQAIR includes a single minimum internal upset taper length of 3.15 inches $(80 \mathrm{~mm})$ covering all drillpipes grades, sizes and weights [33].

According to Wilson [69], the stress concentration factor in the upset region can be reduced if new stress relief tooljoint is designed. Fatigue life of new stress relief tool-joint added with the long taper upset as described previously is approximately four times the life duration of the API upset drillpipe. Anyway, addition of $21 / 2$ inches $(63.5 \mathrm{~mm})$ of

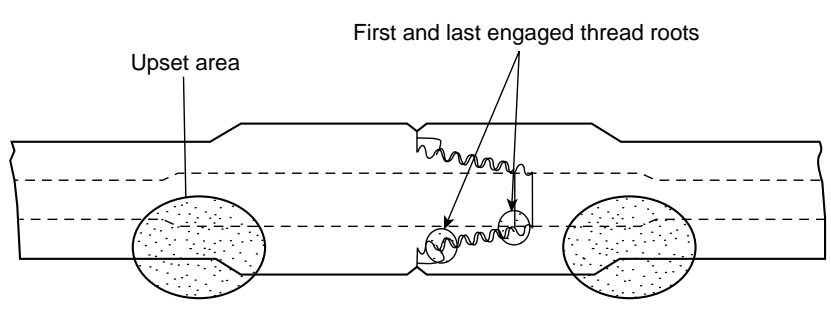

Figure 23

Critical drillstring fatigue areas.

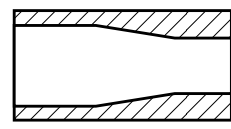

Internal

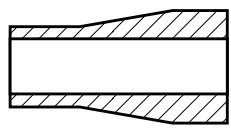

External

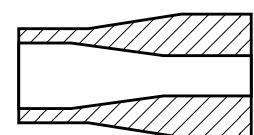

Internal - External
Figure 24

Drillpipe upsets. 
steel is needed in the weld neck of the tool-joint in order to machine the relief groove. These stress relief grooves in the tool-joint reduce the stiffness and allow some flexing, thereby reducing the bending stresses in the drillpipe tube and in the weld area.

Wilson [62] presents a new drillpipe design in order to reduce slip damage problems. Slips are engineered to bite into the pipe to prevent it from slipping down the hole while connections are made up or broken out. Slip cuts are the cause of high stress concentration factor in the drillpipe body (see also Section 1.3). These die-marks are well known to initiate the fatigue cracks. The proposed solution consists of a thick wall tube being welded in between the box tooljoint and the drillpipe upset. This tube has the same wall thickness as the drillpipe upset and the tool-joint weld neck. Length is about $3 \mathrm{ft}(0.914 \mathrm{~m})$ so the gripping system can be set on the thick wall section. Crushing and bending would be improved, as die-marks will not be located in the high stress area.

Shepard [11] note that the current allowable wall thickness tolerance is 12.5-percent. This means that the margin for erosion, corrosion and mechanical damage is very short before pipe is reclassified to Class 2 condition. Specifying 5-percent tolerance should be available and acceptable for most of the pipe manufacturers.

Based on Lubinski's [8] analytical work, Zeren [23] recalls that one of the most important factors affecting the bending of pipe in a dogleg is the distance between two tool-joints. Because it eliminates the problems caused by contact of the pipe with wall of the borehole and therefore reduce the bending stresses, adding one or two protectors, i.e. thickened section the same diameter as the tool-joint is a solution for pipe fatigue improvement.

Sweet [34] has reported the following rate. Approximately 87-percent of all drillpipes failures occurred within 4 stands of the top of the HWDP. Based on these figures, it is recommended to move the bottom 4-5 stands of drillpipes on each trip. Moving the fatigued pipe to a less stressful location should extend the time to failure.

\subsection{Drill Collar Improvement}

Drill collars (DC) are designed to work under compressive loads, to transmit torque to the bit and to resist to internal pressure due to mud flow.

They are trepanned from forged bars. Internal hole is bored and turned. Threaded connections are directly machined on the rod, and most of the time cold rolling is used. Coldworking of the roots of the threads produces residual compressive stresses, which increase the resistance to initiation of fatigue cracks of about 40-percent. Further, gall resistant coating should be applied on new and reworked thread connections.
Improvement is focused on threaded connections, particularly on the last engaged threads because they are the weakest points of the drill collars (Fig. 23). Sweet [34] has reported that 77-percent of the drillstring failures were in the BHA. Approximately 75-percent of the drill collar failures occurred in the bottom (back) of the box connections, near the last engaged thread.

A few papers have dealt with redesigning threads to reduce stress concentration, but most of them restrict interchangeability with $A P I$ standard connections.

Tsukano [70] proposes to redesign the last engaged thread (LET) of the pin by reducing its height of about 70-percent (Fig. 25). This is a quite simple method which allows interchangeability with any standard API connections and then reduces stress concentration on the thread roots. Finite element analyses plus full-scale tests on a four-point bending fatigue testing machine have confirmed this design. The practicability of this connection was tested through overmake-up, make-and-break and full-size tensile and rotating tests. The fatigue limit of the redesigned connection is 1.13 times greater than that of the standard connection.

However, it cannot prevent any box failure at the LET. This type of failure could be avoided by stress relief grooves.

Weiner [71] suggests machining an external stress relief groove in the unengaged portion of the pin and box threads. These stress relief grooves pin or bore back box reduce the stiffness and then allow some flexing. A direct issue is the reduction of the stress concentration factor and then the bending stresses in the drill collar connections. However, it reduces the number of recut and threads remachining. The optimum relief groove, as per [71], should have a diameter which has a cross sectional amount of inertia of about 30 -percent of the cross sectional moment of inertia of the drill collar. See Figures 26 and 27 for further details. Fullsize fatigue tests were conducted on a rotating-bending machine, where the specimens were strain gauges monitored. Testing results show that external stress relief groove connections have life duration 10-times greater than APIInternal Flush (IF) modified connections. For information, $A P I-I F$ means API-IF connections where the internal diameter is constant. API-IF modified connection has internal relief grooves machined at the last engaged thread roots. Note that API-IF connections might now be obsolete.

Based on a detailed two-dimensional finite element analysis, Knight [72] has shown that any stress concentration combined with a modest amount of bore eccentricity in the drill collar may result in a notable reduction in the fatigue life. Whereas the lack of recommendations on drill collar bore eccentricity [9], the bore eccentricity, combined with bending loads, is an important parameter which govern the fatigue life.

Armstrong [73] recalls that on large diameter connections, the low torque face feature is available for drill collar outside diameter larger than 9-inches $(228.6 \mathrm{~mm})$. The low torque face is designed to decrease the make-up torque required and 

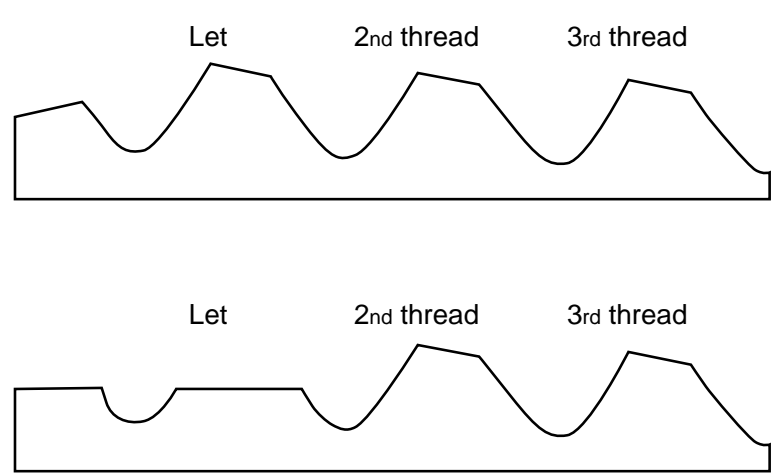

Figure. 25

Redesign of the last engaged thread (LET).

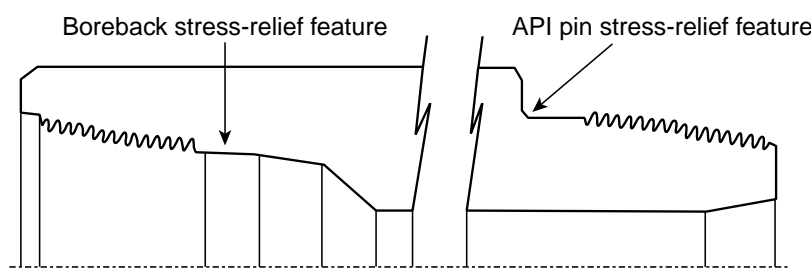

Figure. 26

Box and pin stress relief feature.

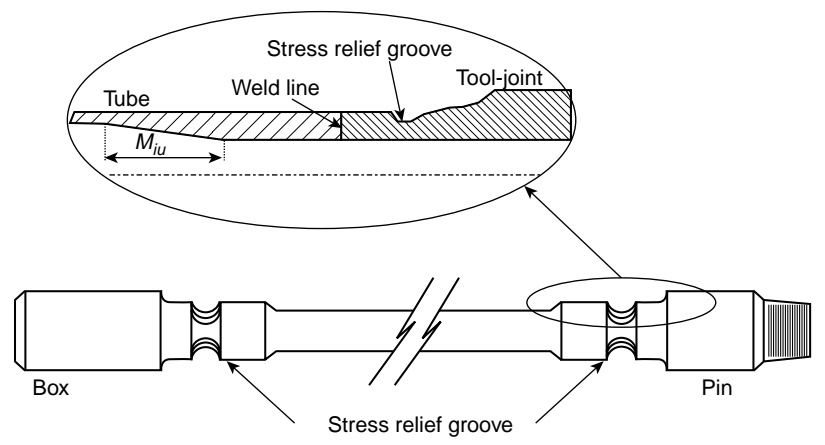

Figure. 27

Tool-joint weld neck stress relief groove.

to increase the bearing stress on the shoulder. Impermeability of the connection is then improved. Compressive stress area of the box is reduced by machining the box to a larger diameter, but tensile stress area remains unchanged in the pin.

Wilson [63] recommends using drill collars close to hole size to reduce bending stresses in the connections and to provide a stiff BHA for controlling deviation. Tapering the drill collar is also important to reduce stress.

\subsection{Heavy W eight Drillpipe Improvement}

Heavy weight drillpipe (HWDP) can withstand tension and compressive loads. They are also calculated to transmit the torque to the bit and resist internal pressure due to the mud flow.

Variation of the cross section inertia of the whole drillstring is reduced when HWDP are run between drill collars and drillpipes. Kirk [74] recommend that the polar section modulus (PSM) ratio should be used to control this change in cross section. The PSM is defined as follows:

$$
\mathrm{PSM}=0.196\left(\frac{D^{4}-d^{4}}{D}\right)
$$

where $D$ is the outside diameter and $d$, the inside diameter. PSM ratio should not exceed 5.5 in normal drilling condition and 3.5 in a corrosive environment.

Moreover in extended reach wells, HWDP increase the weight on bit if they are run in the vertical section of the hole, whereas drill collars are nearly horizontal and their weight on bit is then very low. The buoyed drillstring weight must be multiplied by the cosine of the angle of inclination to determine the amount of usable bit weight. In horizontal wells, drillpipes are sometimes run in compression: drill collars or HWDP must be placed in the vertical or near vertical section of the hole to provide a component of weight for the bit. By using lightweight drillpipes in the horizontal section of the hole, there is less torque and drag which allows drilling a longer horizontal section of hole. But when too much weight is applied, the drillpipes will buckle and become fatigued.

HWDP are made of three parts. Two threaded connections are welded on a forged, bored and turned rod.

Available papers are very poor on HWDP improvement as they are mainly focused on drillpipes and drill collars.

However, Schock [75] proposes to modify the conventional manufacturing procedures. The HWDP are made of a homogeneous one-piece forging of AISI 4145 modified low alloy steel. This integral rotary forging eliminates the weld at the tool-joint, because threads are directly machined on the rod. This HWDP has high strength steel pipe and has a center upset the same diameter as the connection upset. The larger center upset tends to reduce bending loads and can be easily rebuilt. Taper area can also be easily remachined if necessary. Rotary forging provides a smooth grain flow through tapered areas and allows heat treatments. Continuous-line heat-treating increases the depth of hardening to improve the material mechanical properties. Complete transformation to martensite is achieved. This HWDP should enhance fatigue life and reduce stress corrosion cracking tendencies due to the lack of welds.

\subsection{Connections}

This is not the purpose of this paper to describe all the connection nomenclatures and formulae associated, but general information will be reported hereafter. In this case 
the most effective methods to increase connections reliability consist in the optimization of the make-up torque and the selection of the most suitable rotary shouldered connection under certain drilling conditions.

Long thread root radius should be required such as NC (numbered connection), REG (regular), H90 (Hughes 90) but obsolete connections such as IF or FH (full hole) must be avoided. For further details, see [32] or [76]. Optimization and selection of the best-shouldered connections should be calculated with the bending strength ratio BSR, which compares the box and pin stiffness.

$$
\mathrm{BSR}=\frac{Z_{\text {box }}}{Z_{\text {pin }}}
$$

where $Z$ is the section modulus [77]:

$$
\begin{aligned}
& Z_{\text {box }}=0.098 \frac{\left(D^{4}-b^{4}\right)}{D} \\
& Z_{\text {pin }}=0.098 \frac{\left(R^{4}-d^{4}\right)}{R}
\end{aligned}
$$

where $D$ is the outside diameter, $b$, the box thread root diameter at pin end, $R$, the thread root diameter of pin threads $3 / 4$ inch $(19.05 \mathrm{~mm})$ from the shoulder, and $d$, inside diameter of pin.

"API-RP-7G" [9] recommends that BSR varies within the range of 2.25 through 2.75. The lower figure means a weak box whereas the higher threshold means a weak pin. Baryshnikov [77] and Hill [32] propose other BSR figures such as 1.9 to 3.2 .

Based on full-scale fatigue test results, Baryshnikov [77] proposes to enhance the bending strength ratio: the ratio of a box versus pin fatigue limits (FSR) provides the real fatigue resistance in a given environment and allows the selection of the most suitable connections. FSR definition is as follows.

$$
F S R=\frac{M_{\text {box }}}{M_{\text {pin }}}
$$

where $M_{\mathrm{box}}$ is the calculated box fatigue limit as a bending moment for a connection and $M_{\text {pin }}$ is the calculated pin fatigue limit as a bending moment for a connection due to optimum make-up. $M_{\text {box }}$ and $M_{\text {pin }}$ depend on connection fullscale fatigue test results. This method should be quite useful providing that a full-scale fatigue database of all the tooljoints is existing. However, fatigue tests on threaded joints are usually very costly and time-consuming compared to a calculation approach, e.g. using finite element analysis and fracture mechanics.

Most standard tool-joints are weaker in torsion than the tubes to which they are welded. All API tool-joints, except those on HWDP or those in Grade E 75, have the same minimum yield strength of 120000 psi (827.4 MPa), regardless of the grade of pipe to which they are attached. Therefore, make-up torque for connections is determined only by the tool-joint pin internal diameter or box outside diameter. Make-up torque of a tool-joint is the maximum torque to be applied on the drillstring and not the torque capacity of the tool-joint. Make-up puts elastic stretch in pin and compression in box. Recommended make-up torque for rotary shouldered connections is the amount of torque required to achieve a 60-percent of its minimum yield strength, i.e. $72000 \mathrm{psi}$ (496.4 MPa) for used tool-joints. For new tool-joint, intended for break-in only, 50-percent of its minimum yield strength is required. 57-percent for drill collars with diameters of less than 7" $(177.8 \mathrm{~mm})$ and 62-percent for drill collars with diameters of more than 7 " $(177.8 \mathrm{~mm})$ are recommended by "API-RP-7G" [9]. API make-up torque figures should be taken from tables given in [32] or [76].

Baryshnikov [78] proposes to calculate the optimal makeup torque value from the actual material yield strength and not the minimum yield strength as suggested by API [9].

If pin and box are not correctly preloaded, the seals may separate under downhole side loads. If insufficient preload is applied, the torque shoulder may open allowing drilling fluid to pass through the threads and across the torque shoulder. This effect called wobbling may lead to washout, then rapidly to failure. Likewise, excessive make-up torque will result in high tool-joint stresses and can also lead to more rapid fatigue failure. A basic rule to avoid downhole makeup is to limit operational design torque value lower than make-up torque value.

“API-RP-7G" Equations [9] are defined with a safety factor of 1.1. Bailey [79] has reported that this safety margin may not be sufficient for cases involving high pressure, severe bending or downhole dysfunction caused by vibrations.

Moreover, the friction factor of the thread dope must always be reported, as the make-up torque equation should be revised. Range is from 0.8 for lead or zinc based compounds through 1.27 for copper based compounds [80].

The friction factor standard laboratory test procedure is fully described in "API-RP-7A1" [81]. However, this API recommendations is based on small diameter bolt results and cannot be applied to correct the recommended make-up torque directly at the rig site. The previous API version [82] is closer to reality as it is based on full-scale tool-joint, but it is not operative and not applicable at the rig site. Baryshnikov [83] proposes to evaluate periodically the friction factor directly on the real connections at the rig site using existing equipment and then correct the recommended make-up torque value. This friction factor is determined as a function of actual make-up and breakout torque periodically measured on site. 
Payne [80] has reported that high-friction thread compounds have now been successfully implemented on critical extended reach well operations with increased make-up torque. Baryshnikov [84] reports that friction factor may widely change when threads get used. The API tool-joint classification (New, Premium and Class 2) is based on outside diameter variations and does not reflect the actual thread state. Therefore, Baryshnikov recommends to periodically establish a rotary shouldered connection friction capacity depending on the number of make-up and break out carried out during the drillstring service. Connection friction capacity may vary within a large range, more than 50-percent, during connection life and from one assembly to the other [83]. Recommended make-up torque values are thus corrected based on the thread connection wear classification and the combined loads such as tension, torsion and make-up torque $[83,84]$.

In order to increase the drilling torque, the make-up torque value should be increased with the remaining 40-percent of pin yield capacity. But as make-up is increased, the pin is exposed to higher tension at make-up and is then able to support less subsequent applied tension. When the operating tension can be confidently forecast and monitored below the maximum tension available at nominal make-up torque, torque capacity can be increased by an engineered reduction in tension capacity.

It is worth to mention that Slack [85] has developed a new contact pressure measurement technology. Application of this measurement for connection make-up should differentiate connections with inadequate prestress either due to manufacturing out of tolerance, defects or insufficient makeup torque or rotation. This method is based on an ultrasonic reflection amplitude pressure correlation (URAP), and it enables direct evaluation of the integrity of metal-to-metal seals within premium connections.

Another way of increasing the torsion capacity of tooljoints is the introduction of the multiple torque shoulders. Double-shoulder tool-joints offer 40-60 percent higher torsion capacity than conventional API single shoulder [80]. Further, they provide better hydraulic capacity due to their slimmer dimensions.

Based on finite element analysis, Tafreshi and Dover [22] have shown that a further decrease in stress concentration factor (SCF) was possible with slight modification to the thread geometry. Their results showed that the thread root should not be modified for the box because it creates very high SCF on unengaged teeth in the box, but some improvement is possible for the pin. Assuming a constant cutback, increasing root radius is recommended to reduce the SCF, but a limit would be reached after which the SCF increases. The maximum SCF in the first engaged tooth of the pin depends on the ratio root radius $r$ on cutback length $L$ (i.e. $r / L$ ) and reaches a minimum value when $r / L=0.8$. Other thread profiles have been analyzed through sensitive studies using the following parameters: thread root radius $r$, blend radius $R$, cutback length $L$ and length of the pin stress relief.

Grant Prideco has put on the market the "H-Series

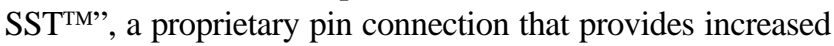
durability and fatigue resistance. The SST involves a modification to the pin thread only. The mating box thread remains standard and the connection is completely interchangeable with the standard API NC connections. The SST pin incorporates two primary features. First, the thread form has an enlarged root radius. Second, the pin thread body is machined on a slightly flatter taper than that of the box, effectively behaving like a variable pitch thread. These SST features provide improved fatigue life.

Anyway, these analyses confirm that for any type of loading the location of maximum SCF is at the root of the first engaged tooth of the pin and the last engaged tooth of the box.

\subsection{Improvement of Steel Properties}

Another way of improvement is to enhance the steel mechanical properties instead of modifying the geometry.

Section 5.3 has proposed to use conventional AISI 4145 steel pipe with higher mechanical properties by changing the manufacturing methods [71].

Tsukano [86] suggests employing 165-ksi (1137.6 MPa) grade material to redesign the drillpipes. The stress concentrations at upset transitions were completely redesigned in order to prevent any fatigue failures. With standard tooljoints manufactured from $120 \mathrm{ksi}(827.4 \mathrm{MPa})$ yield material, a $165 \mathrm{ksi}(1137.6 \mathrm{MPa})$ drillpipe product, with $165 \mathrm{ksi}$ (1137.6 MPa) tool-joints, offers a 38-percent increase in tooljoint torque and tension capacities. The hydraulic loss through the drillpipe was also considered. Moreover, the pipe weight has been reduced by decrease of the wall thickness using high strength steel. The author claims that the corrosion fatigue property is superior to that of S-135 and the resistance to high temperature is also good. Full-size tests such as torsion tests, tensile tests, fatigue tests, burst and collapse tests were conducted to validate the design. However, no economic point of view versus standard drillpipes is mentioned.

\subsection{Aluminium and Titanium Alloys}

A very few papers deal with aluminum drillpipe, as it is not widely used (except in Russia). Glagola [87] recalls that aluminum drillpipe provides solutions for many problems encountered in directional drilling such as lighter weight than steel, reduction of drillstring drag and torque, increase of fatigue life, and therefore decrease of wears on tool-joint, pipe body and casing. Aluminum has a great flexibility when the drillstem is subjected to unusual stretching, bending and 
twisting loads. However, Glagola has compared aluminum with only $E$ and $D$ grade steel. Payne [80] stated that aluminum drillpipe has not made the market penetration that might have been anticipated, given its advantages over steel drillpipe. Firstly, because the relatively low yield strength compared to high strength steel limits its applicability in complex wells. The aluminum alloy used for drillpipe has yield strength of $58000 \mathrm{psi}(400 \mathrm{MPa})$. The tool-joints for aluminum drillpipe are manufactured from steel. Secondly, aluminum drillpipe requires new procedures for planning and executing drilling operation. Moreover, Payne has reported that several aluminum drillpipes have suffered significant mid-body wear and corrosion problems, mainly due to mud $\mathrm{pH}$, chlorides and oxygen, high temperature and storage. Mainly due to the reduced hookload capacity, the field is open to optimized drillpipe design for extended reach wells where the use of an aluminum drillpipe at the bottom of a S-135 grade steel drillstring is possible. According to Grant Prideco, aluminum cost is about 4-times the cost of a comparable steel product.

Titanium drillpipes are described by Payne [80]. Titanium alloys have a lower density and elastic modulus than steel, and can achieve higher yield strength. Advantages are the weight saving combined with the increased buoyancy. However, helical buckling and torsion twist remains an area for further investigation due to its low elastic modulus. Wear resistance is also very bad and the cost is about 8-10 times the cost of a comparable steel product.

\subsection{Tool-Joints Hardfacing}

Regarding tool-joints abrasion, Schenato [88] recommends to use tool-joints with consistent layers of hard material welded on the external side, when drilling in abrasive deep hard rocks. This can dramatically increase the fatigue life of the connections and the worn out material in the tool-joint can be easily restored. However, the selection of an appropriate tooljoint hardfacing is critical, as the result can be a rapid casing wearing. Payne [80] reports that chromium based hardmetals eliminate casing wear problems compared to tungsten carbide hardfacing.

Eaton [89] reports that 57-percent of the joints of the Auger's drillstring had cracks in tool-joints. Heat checking is the main cause of these discovered cracks. Heat checking phenomenon can be explained as follows. After being heated by friction, steel is quenched by the drilling fluid. Heating above the critical temperature yields to austenite creation. Rapid cooling of the metal transforms the austenite to hard untempered martensite which is susceptible to crack formation. Hardbanded tool-joints with metamorphic alloy may help to reduce heat generation and thus heat checking. Moreover, it has shown lower casing wears.

Another way to reduce heat checking is to decrease the side loads, the velocity of tool-joints at contact surface and the coefficient of friction at this point. Side loads are a function of drillstring tension and dogleg severity. Lubinski has defined empirical curves in "API-RP-7G" [9] where the lateral force on tool-joint is given versus the dogleg severity and the buoyant weight suspended below the dogleg. These curves are the only available data to estimate the maximum allowable side loads without computer. Note that a flex joint above a subsea blow out preventer (BOP) stack is said to be a severe dogleg where the side loads are important. The velocity at a point on the outside diameter is proportional to the change in tool-joint outside diameter. The friction factor depends on the mud being used, e.g. from 0.15 for an oil base fluid to 0.33 for a water based fluid.

The same phenomenon is reported when hardbanding is welded on tool-joints without pre-heating or post-heating. Steel is heated during the welding and quenched by the air, hard untempered martensite is then created from the austenite. The equivalent carbon (EC) relationship is an empirical relationship as recalled in (32) where percentage of steel cheminal elements are taken into account. Pre- or postheating is recommended when EC $>0.4 \%$.

$$
\begin{aligned}
E C & =C(\%)+\frac{M n(\%)}{6} \\
& +\frac{[C r(\%)+M o(\%)+V(\%)]}{5}+\frac{[C u(\%)+N i(\%)]}{15}
\end{aligned}
$$

\subsection{Toughness}

Toughness is a measure of material's ability to resist crack or notch extension. Thereby, tough material can sustain a larger crack before final failure. "API Specification 5D" [36] has adopted in 1992 minimum toughness recommendations for drillpipes. The Chevron Corporation has issued this empirical criterion and it suggests $54 \mathrm{~J}$ at room temperature for 3/4 size Charpy impacts. It is based on field observations. However, no requirement is existing for tool-joints and bottom hole assembly (BHA). Hill has reported that five of the six brittle fractures observed in his study [4] occurred in tool-joints or BHA connections. Therefore, minimum toughness standard should be issued for the whole drillstem including BHA and tool-joints.

Szklarz [90] proposes the same approach. This has allowed the application of a room temperature, $80 \mathrm{~J}, 3 / 4$ size Charpy criterion in Shell Canada drilling contracts. However, material in accordance with Shell's criterion is 30 to 50-percent more expensive than API steel. Shell's recommendations for HWDP and drill collars are an impact resistance of $42 \mathrm{~J}$ at room temperature [33].

These reasonable requirements could mean the difference between a detectable washout and a final twist-off. This washout would be detectable by instrumentation and/or the rig crew through the loss in mud pump pressure. 


\subsection{Classification and Marking}

Most of the effort in drillstem design is usually concentrated on the operating characteristics of the pipe and tools. However, fatigue failure could be significantly reduced by involving people both in planning, indexing and selecting drillpipes with appropriate mechanical and performance properties.

Armstrong [73] focuses on the connections by analyzing and identifying their characteristics in order to minimize weaknesses. To reduce the risk of failure, the author recommends to select the connectors based on the following:

- selecting the connection outside diameter based on a wellby-well drilling plan, availability of drillstem equipment and rig equipment capacities;

- optimizing the connection choice by checking coefficients such as bending strength ratio, torsion strength and area ratio and by selecting stress and damage resistant properties;

- establishing operational limits for make-up torque, dimensional wear limits and for external load capacity to identify potential source of failure while the equipment is in use.

Schenato [88] insists on the pipe follow-up. People should be involved in reliability enhancement as well as in followup. Among all personnel, an awareness should be created and procedures should be implemented to highlight how failures occur and how they may be reduced. The development of a standardized "Report Form" should be used for recording and analyzing reported failures.

As per Horbeek [33], the greater awareness benefits are made during drillstring failure prevention training courses. A twist-off free footage award scheme has been achieved in Shell's rigs in order to encourage washout detection by everyone. Each twist-off costs Shell Expro on average $£ 250000$. Washout on the other hand cost ten times less than twist-off [33]. New generation gauges which can utilize "Smart Alarms" to account for the pressure lost when washout occurs should be implemented. A further benefit identified by Horbeek [33] was that the voltage generated by the tool's turbine is proportional to the flow through it and as such could be used to detect washout above the MWD (measurement while drilling ) tool.

To improve the follow-up, Schenato from Agip [88] proposes a two codes automatic system, one for the type of pipe, and one for the pipe type numbering. Similarly, Shell Expro [33] has developed electronic pipe tagging and has now more than a one-year field trial on two Brent platforms.

As per [88], Agip should set up an advanced drilling information system. This expert system can help in decision making support to both planning and supervision of drilling activities. The first step is the creation of a historical database. This step is essential, as fatigue failure is the result of cumulative damages. Inspection results such as non-destructive tests (NDT) should be included in this database. Further improvement will be rig site sensors analysis as well as the development of a data collection system.

Anyway, amount of logging-while-drilling data and conventional wireline data collected are continuously growing. Horbeek [33] reports that MWD shock logs can warn of impending drillstring failure. Internal partnering between drilling specialists and geologists may ensure that only needed data is recorded. These data should be analyzed at each step, then methodology would be improved as well as planning. We are confident that a data base system such as an electronic chip bonded on a drillpipe and wireless linked to a computer able to read and write on this chip is necessary to monitor fatigue using actual drilling information as well as fatigue computation which are described in the next section.

\section{ON-GOING PROJECTS DEVELO PED BY IN STITUT FRAN ÇAIS DU PÉTRO LE}

Institut français du pétrole (IFP) is currently working on a global project where the fatigue of the drillpipes is investigated with the cooperation of several companies involved in the drilling industry. The aim is to issue both recommendations regarding the fatigue failures and enhancement on drillpipes geometry, steel properties and fabrication procedures. This project is split in several tasks, which are summarized hereunder.

\subsection{Stresses Computation in a Whole Drillstem}

The aim of this task is to compute the stresses in a whole drillstem inside a borehole. A drilling package is being developed from an in-house software which is existing and validated. Specific boundary conditions can be introduced in order to take into account the bit behavior.

The software enables to take into account the geometrical definition of the bore and drillpipes as well as nonlinear phenomena such as friction, contact and buckling in dynamic conditions. Life duration and cumulative damage will be then post-processed.

In the second year of the project, the vibrations will be simulated through dynamic computation. Specific boundary conditions on the bottom hole assembly (BHA) and bit will be implemented to reflect the vibration dysfunction. They will be validated using the Trafor database. Trafor is a drilling equipment developed by IFP and dedicated to record drilling parameters such as accelerations both near the bit and on surface [91, 92]. A large set of vibration effects has been recorded during years of drilling campaigns and is available.

A set of loads from a piece of the drillstring can be imported in a finite element model as boundary conditions in order to perform a local analysis. 


\subsection{Lab-Tests and Finite Element Analyses}

IFP is testing coupons of $4145 \mathrm{H}$ steel in order to obtain the $S-N$ curves. These toroïdal specimens were machined from a piece of drill collar at two radii: close to the wall and in the metal core. They are tested in cyclic axial tension loading with a stress ratio of $R=0.1$.

Oligocyclic fatigue is the second set of tests performed by IFP. Cylindrical coupons are tested in cyclic axial tension loading with a constant strain amplitude. A nonlinear elastoplastic model is then fitted for the $4145 \mathrm{H}$ steel in order to model the elastoplasticity behavior in a finite element software.

Finite element analyses are performed using the Abaqus software, including nonlinear material laws fitted with labtests. A set of loads is imported from previous computations in the whole drillstring. Enhancement of geometry such as thread shape and taper, steel properties and fabrication procedures (e.g. cold-rolling) could then be optimized for a given load set obtained by computations carried out in Section 6.1.

\subsection{Failed Specimens Examination}

Failed drillstrings are examined in order to issue detailed analyses of the failures. The survey identifies the cracks, their location, their cause, the way they initiate and propagate. Analyses procedures and recommendations are being issued in order to understand better the fatigue failure.

Recommendations are provided on:

- identifying and protecting the failed drillpipe;

- cleaning and transportation of the specimen;

- recording on-rig information;

- how to perform a complete examination including destructive and nondestructive tests.

Inspection of failed-drillpipes will be carried out by this project in order to understand better fatigue cracks location, the way they initiate and propagate and how to improve inspection methods.

\section{CONCLUSION}

Fatigue in drillstring may occur if pipe is rotated and crooked, i.e. bent, buckled or submitted to vibrations.

Cracks may appear in stress concentration areas such as slip cut, upset area, thread roots or corrosion pits. Improvements will be mainly focused on these points.

Autopsies on fatigue cracks should always be carried out. Fatigue cracks can be recognized as they are most of the time flat and orientated perpendicular to the pipe axis.

The following summarized the actions to reduce fatigue in drillstring:
- Reduce cyclic stress level. Dogleg severity should be monitored in order to calculate the cumulative damage. Buckling should be avoided, mainly in drillpipes. Vibrations should be reduced and monitored. Rotation should be limited as much as possible.

- Reduce effects of stress concentrators. Most of the drillstring new designs are achieved in these high stress areas.

- Reduce corrosion effects. Corrosion should be monitored; inhibitors and scavengers should be used.

- Increase material properties such as fracture toughness. Washout before twist-off is then possible.

- Fatigue tests are carried out in order to validate material characteristics and to test any new designs before using downhole. Fatigue tests on small-scale samples should allow cost and time reduction.

- Inspection procedure and standard should be specified.

Anyway, we believe there is a lack of standard recommendations in all the previous points. Enhancement is necessary in fatigue damage calculations, where dynamic effects such as vibrations should be taken into account in the whole drillstring. Connection design may be improved as well.

\section{REFEREN CES}

1 Joosten, M.W. (1985) New Study Shows How to Predict Accumulated Drillpipe Fatigue. Word Oil, October.

2 Dale, B.A. (1988) An Experimental Investigation of FatigueCrack Growth in Drillstring Tubulars. SPE Drilling Engineering, 356-362, December.

3 (1992) Ten Ways to Reduce Drilling Costs. Petroleum Engineer International, September.

4 Hill, T.H. (1992) A Unified Approach to Drillstem Failure Prevention. SPE Drilling Engineering, December.

5 Pitts, J.P. Trip Inspection, Testing Gain Favor as Insurance. Drill Bit, 303, 885.

6 Lieurade, H.P. (1982) La pratique des essais de fatigue. Commission Fatigue des métaux de la SFM, Pyc Edition, Paris, France.

7 Lubinski, A. (1961) Maximum Permissible Doglegs in Rotary Boreholes. Journal of Petroleum Technology, February.

8 Hansford, J.E. and Lubinski, A. (1966) Cumulative Fatigue Damage of Drillpipe in Doglegs. Journal of Petroleum Technology, March.

9 API (1998) Recommended Practice for Drillstem Design and Operating Limits. API-RP-7G, 16th ed., August.

$10 \mathrm{Wu}$, J. (1997) Model Predicts Drillpipe Fatigue in Horizontal Wells. Maurer Engineering Inc., Oil and Gas Journal, February 3.

11 Shepard, J.S. (1992) Extended Drillpipe Life with Tighter Specifications. Global Marine Drilling Co., IADC/SPE 23843, February.

12 Wu, J. (1996) Drill-Pipe Bending and Fatigue in Rotary Drilling of Horizontal Wells. Maurer Engineering Inc., SPE 37353, October. 
13 Paslay, P.R. and Cernocky, E.P. (1991) Bending Stress Magnification in Constant Curvature Doglegs with Impact on Drillstring and Casing. SPE 22547, October.

14 Howard, J.A. (1993) Systematic Tracking of Fatigue and Crack Growth to Optimize Drillstring Reliability. Enertech Engineering and Research Co., SPE/IADC 25775, February.

15 Smith, J.E. (1992) Drillpipe for Horizontal Drilling. SPE 23990, March.

16 Hill, T.H. (1995) Designing and Qualifying Drillstrings for Extended Reach Drilling. SPE/IADC 29349, Drilling Conference, Amsterdam, February 28-March 2.

17 Dawson, R. and Paslay, P.R. (1984) Drillpipe Buckling in Inclined Holes. Journal of Petroleum Technology, October.

18 He, X. and Kylingstad, A. (1993) Helical Buckling and Lock-up Conditions for Coiled Tubing in Curved Wells. SPE Asia-Pacific Oil and Gas Conference, SPE 25370, February.

19 Baryshnikov, A. (1997) Downhole Tool Serviceability Under Dynamic Loads. Drilling Conference SPE/IADC 37647, Amsterdam, March 4-6.

20 Rahman, M.K. (1999) Stress Concentration Incorporated Fatigue Analysis of Die-Marked Drillpipe. International Journal of Fatigue, Elsevier, 21, 799-811, January.

21 Grondin, G.Y. (1994) Fatigue Testing of Drillpipe. SPE Drilling and Completion, June.

22 Tafreshi, A. and Dover, W.D. (1993) Stress Analysis of Drillstring Threaded Connections Using the Finite Element Method. International Journal Fatigue, 15, 5, 429-438, September.

23 Zeren, F. (1986) Fatigue Limits Analyzed for Drillpipe in a Dogleg. Oil and Gas Journal, September, 22.

24 Ertas, A. (1989) The Effect of Tool-Joint Stiffness on Drillpipe Fatigue in Riser Ball Joints. Journal of Engineering for Industry, 111, November.

25 Ertas, A. (1992) A Comparison of Fracture Mechanics and S-N Curve Approaches in Designing Drillpipe. Journal of Offshore Mechanics and Artic Engineering, 114, August.

26 Placido, J.C.R. (1994) Drillpipe Fatigue Life Prediction Model Based on Critical Plane Approaches. OTC 7569, Houston, Texas, May 2-5.

27 Chen, W.C. (1990) Drillstring Fatigue Performance. SPE Drilling Engineering, June.

28 Ertas, A. A Comparison of Fracture Mechanics and S-N Curve Approaches in Designing Drillpipe. Mechanical Engineering Department, Texas Tech. University, Lubbock, Texas.

29 Kral, E. (1984) Fracture Mechanics Concept Offers Model to Help Calculate Fatigue Life in Drillpipe. Technology, Oil and Gas Journal, August, 13.

30 Lemaître, J. and Chaboche, J.L. (1996) Mécanique des matériaux solides. 2nd ed., Dunod, Paris, France.

31 Hill, T.H. (1985) Qualifying Drillstring Components for Deep Drilling. Journal of Petroleum Technology, August, 1511-1522.

32 Hill, T.H. (1998) Standard DS-1, Drillstem Design and Inspection. T.H. Hill Associates Inc., DEA Project 74, 2nd ed., March.

33 Horbeek, J.H. (1995) Successful Reduction of North Sea Drillstring Failures. Offshore Europe SPE 30348, Aberdeen, September, 5-8.

34 Sweet, R.G. (1989) Case History of Drillstem Failures Offshore West Africa. Drilling Conference SPE/IADC 18653, New Orleans, February 28-March 3.
35 Kahil, J. (1989) New Technology for the Inspection of Used Tubing and Drillpipe. Eighth International Conference on Offshore Mechanics and Artic Engineering, 327-332, The Hague, March 19-23.

36 API (1999) API Specification 5D, Drillpipe, 4th ed., August.

37 API (1997) Recommended Practice for Field Inspection of New Casing, Tubing and Plain End Drillpipe. API-RP-5A5, 6th ed., December.

38 Wade Edens, C. () Recent Innovation in Flux Leakage Drillpipe Inspection Technology: Quality Control Enhanced. Oilfield Equipment Marketing Inc., South Texas Chapter ASNT, 515, 860.

39 Shaffer, E.A. (1992) Drillstring Problems Related to Internal Upset-Run-Cut Area of Drillpipe. Tuboscope Inc., Drilling Conference, New Orleans, February 18-21.

40 Armstrong, G.M. (1985) Sensitivity and Application of the Normal Beam Ultrasonic Technique for Detection of Fatigue Cracks in Rotary Shouldered Connections. SPE/IADC 13430, March.

41 Chapman, P.W. (1986) Ultrasonics Finds Drillpipe Cracks. Drilco, Petroleum Engineer International, March.

42 Stanley, R.K. and Wells, L. (1994) Recent Advances in Used Drillpipe Inspection by Ultrasonic Methods. Material Evaluation, 1282-1285, November.

43 Ananto, D. (1996) Determining Drillpipe Wear Inside Casing Using Ultrasonic Measurements. Twenty-fifth Silver Anniversary Convention, Indonesian Petroleum Association, Proceedings, October, 411-423.

44 Walaszek, H. (1998) Le contrôle ultrasonore possible aujourd'hui sans couplant ? Présentation de quelques résultats obtenus au CETIM. CETIM, Service CND, Senlis, France, May.

45 Dale, B.A. (1988) Inspection Interval Guidelines to Reduce Drillstring Failures. Exxon, Drilling Conference SPE/IADC 17207, Dallas, Texas, February 28-March 2.

46 (1982) Drillpipe Inspection Technique. The Oilman, November, 33.

47 Ligrone, A. (1995) Reliability Methods Applied to Drilling Operations. Agip SpA, Drilling Conference, Amsterdam, February 28-March 2.

48 Yoder, D.L. (1991) An Integrated Approach to Enhancing the Mechanical Life of Drillpipe in Extended Reach Wells. OTC 6712, Houston, Texas, May 6-9.

49 Gensmer, R.P. (1988) Field Correlation Between Internal Taper Length and Tube Failures in 4.5-in. 16.60E, IEU Drillpipe. Noble Drilling Corp., Drilling Conference IADC/SPE 17205, Dallas, Texas, February 28-March 2.

50 Gonzalez-Rodriguez, J.G. (1992) Corrosion Fatigue of AISI 4145 Steel in Drilling Mud. NACE Annual Conference and Corrosion Show, 151.

51 Seshadri, P.V. (1992) Drillstring Failure Database: What Do We Learn? API/IADC, Drilling Conference IADC/SPE 23842, New Orleans, February 18-21.

52 Brennan, F.P. (1995) Fatigue of Drillstring Connections. Transaction of the ASME, 117, May.

53 Hatcher, P.R. and Szklarz, K.E. (1992) Near-Threshold Fatigue Crack Propagation Behavior of a Low Alloy Steel in Pressurized Dilute Brine Solution. NACE Annual Conference and Corrosion Show, 150.

54 Grondin, G.Y. and Kulak, G.L. (1989) Fatigue of Drillpipe. CADE/CAODC Spring Drilling Conference, 89-47, April.

55 Baryshnikov, A. (1997) Downhole Tool Full-Scale Fatigue Test: Experience and Practice Recommendations. ASME, 
8th Annual International Energy Week Conference and Exhibition, Houston, Texas, January 28-30.

56 Trishman, L.E. (1952) Methods for the improvement of Drill Collar Joints Evaluated by Full-size Fatigue Tests. Spring Meeting of the Southwestern District, Division of Production, Shreveport, March.

57 Gaynor, T.M. (1996) Reduction in Fatigue Failures through Crack Detection by Alternating Current Field Measurement. Drilling Conference IADC/SPE 35033, March.

58 Azar, J.J. (1979) How $\mathrm{O}_{2}, \mathrm{CO}_{2}$ and Chlorides Affect Drillpipe Fatigue. Petroleum Engineer International, March.

59 Jiashen, Z. and Jingmao, Z. (1993) Increasing the Fatigue Life of 40-Cr Steel in Drilling Muds with Corrosion Inhibitors. NACE Corrosion, 49, 3, March.

60 Karim Khani, M. (1996) Corrosion Fatigue in Nitrocarburized Quenched and Tempered Steels. Metallurgical and Materials Transactions, $\mathbf{2 7 A}$, May.

61 Hendrickson, J.R. and Holland, M.R. (1984) Drillpipe Failures in Hydrogen Sulfide. Drilling Technology Conference Transactions, 358, 516, March.

62 Wilson, G.E. (1996) A New Drillpipe Design Virtually Eliminates Failures That Result from Slip Damage. Drilling Conference IADC/SPE 35036, New Orleans, March 12-15.

63 Wilson, G.E. (1998) How to Reduce Drillstring Fatigue Failures in a Corrosive Environment. Drilling 98, World Oil, October.

64 API (1997) Standard Procedure for Field Testing WaterBased Drilling Fluids. API-RP-13B-1, 2nd ed., September.

65 API (1998) Standard Procedure for Field Testing Oil-Based Drilling Fluids. API-RP-13B-2, 3rd ed., February.

66 Tsukano, Y. (1988) Appropriate Design of Drillpipe Internal Uset Geometry Focusing on Fatigue Property. Drilling Conference IADC/SPE 17206, Dallas, Texas, February 28March 2.

67 Winship, T.E. (1995) Making Drillpipe Upsets which Increase Fatigue Life. Spring Drilling Conference CADE/CAODC, 95-1009, Calgary, April.

68 Wilson, G.E. (1994) What difference Does Internal Taper Length Make on Drillpipe Fatigue Life? Drilling and Completion, SPE 23841, March.

69 Wilson, G.E. (1993) A New Tool-Joint Design Increases the Fatigue Life of Drillpipe Tubes. Drilling Conference SPE/IADC 25772, Amsterdam, February 23-25.

70 Tsukano, Y. (1990) Improvement of Drill Collar Fatigue Property by Last Engaged Thread Height Reduction of Pin. Drilling Engineering, SPE 18704, December.

71 Weiner, P.D. (1972) A Means of Increasing Drill Collar Connection Life. Transactions of the ASME, Journal of Engineering for Industry, ASME 72-Pet-65.

72 Knight, M.J. (1999) Fatigue Life Improvement of Drill Collars Through Control of Bore Eccentricity. Engineering Failure Analysis, 6, 301-319.

73 Armstrong, G.M. (1987) Failure Prevention by Selection and Analysis of Drillstem Connections. Drilling Conference SPE/IADC 16075, New Orleans, March 15-18.

74 Kirk, W.L. (1972) Deep Drilling Practices in Mississippi. Journal of Petroleum Technology, June.
75 Schock, W.H. (1986) One Piece, Forged, Heavy Wall Drillpipe: Built Stronger for Tougher Drilling. Drilling Conference IADC/SPE 14792, Dallas, February 10-12.

76 Gabolde, G. and Nguyen, J.P. (1999) in Drilling Data Handbook, Publications de l'Institut français du pétrole, Éditions Technip, 7th ed., Paris, France.

77 Baryshnikov, A. (1994) Optimization of Rotary-Shouldered Connection Reliability and Failure Analysis. Drilling Conference IADC/SPE 27535, Dallas, February 15-18.

78 Baryshnikov, A. (1995) Downhole Tools Fatigue Resistance for Different Materials. Drilling Technology, ASME, $\mathrm{PD}, \mathbf{6 5}$.

79 Bailey, E.I. (1998) Calculating Limits for Torsion and Tensile Loads on Drillpipe. Hart's Petroleum Engineer International, February.

80 Payne, M.L. (1995) Drillstring Design Options for Extended Reach Drilling Operations. Drilling Technology, ASME, PD, 65.

81 API (1992) Recommended Practice for Testing of Thread Compound for Rotary Shouldered Connections. API-RP-7A1, 1st ed., ANSI/API-RP-7A1-1992, November.

82 API (1983) Tentative API Bulletin on Rotary Shouldered Connection Thread Compounds. Bulletin API-7A1, 1st ed., February 1980 and Supplement 1, March 1983.

83 Baryshnikov, A. (1995) Make-up Torque and Rotary Shouldered Connection Reliability. Drilling Conference SPE/IADC 29352, Amsterdam, February 28-March 2.

84 Baryshnikov, A. (1999) Eliminating Twist-Offs as a Cause of Drillstring Failure. OCTG Special Report, Word Oil, July.

85 Slack, M.W. (1990) Technique to Assess Directly Make-up Contact Stress Inside Tubular Connections. Drilling Conference IADC/SPE 19924, Houston, Texas, February 27March 2.

86 Tsukano, Y. (1990) Development of Lightweight Steel Drillpipe with 165-ksi Yield Strength. Drilling Conference IADC/SPE 19960, Houston, Texas, February 27-March 2.

87 Glagola, M.A. (1986) Aluminium Drillpipe for Directional Drilling. Drilling Conference IADC/SPE 14789, Dallas, Texas, February 10-12.

88 Schenato, A., Borriello, G. and Pozzi, V. (1991) Ultra Deep Drilling Problems and Solutions, Agip SpA, Milano, Italy.

89 Eaton, L.F. (1993) Tool-Joint Heat Checking While Predrilling for Auger TLP Project. Drilling Conference SPE/IADC 25776, Amsterdam, February 23-25.

90 Szklarz, K.E. (1990) Fracture Toughness Criteria for HighStrength Drillpipe. Shell Canada Ltd, Drilling Conference IADC/SPE 19964, Houston, Texas, February 27-March 2.

91 Guesnon, J. and Pignard, G. (1992) IFP Field Tests its New Trafor MWD System. Ocean Industry, May, 23-28.

92 Mabile, C., Fay, J.B. and Desloovere, O. (1997) Standard Surface Measurements Sampled at High Acquisition Rate Help in Detecting Drill String Vibrations. Offshore Mediterranean Conf. OMC 97, Ravenna, Italy, March 19-21, 759-769.

Final manuscript received in October 2001 